\title{
ANHELOS, REALIDADES Y SUEÑOS ANTE LA PERSPECTIVA Y URGENCIA DE LA EDICIÓN CRÍTICA DIGITAL. REFLEXIONES DESDE UN GRUPO DE INVESTIGACIÓN
}

\author{
Ramón Valdés (Prolope, Universitat Autònoma de Barcelona)
}

Fecha de recepción: 09-12-2013 / Fecha de aceptación: 29-12-2013

Cita ReComendada: Ramón Valdés Gázquez, "Anhelos, realidades y sueños ante la perspectiva y urgencia de la edición crítica digital. Reflexiones desde un grupo de investigación», Anuario Lope de Vega. Texto, literatura, cultura, XX (2014), pp. 1-46.

DOI: <http://dx.doi.org/10.5565/rev/anuariolopedevega.86>

\section{Resumen}

En este artículo se reflexiona sobre la carencia de ediciones críticas digitales en el ámbito del teatro español del Siglo de Oro, y sobre su necesidad. Se muestran las ventajas de las ediciones digitales sobre las ediciones en papel para algunos casos textuales (según la transmisión de la obra) y se proponen métodos de presentación dinámicos e interactivos para procesos genéticos u obras con distintas versiones, así como con dificultades especiales de anotación. Se plantean cuestiones de gestión de la investigación relacionadas con proyectos digitales, así como de divulgación y preservación de los resultados científicos y se debate a propósito de la facilidad de uso y suficiente desarrollo o no de las herramientas digitales para acometer ediciones críticas digitales en grandes proyectos de edición. Se concluye la necesidad y urgencia de acometer ediciones críticas digitales, pero también de desarrollar más y hacer más amigables los lenguajes y software destinados a la edición de textos.

Palabras Clave: Edición crítica digital; gestión de proyectos de investigación; gestión de proyectos de Humanidades Digitales; casos textuales; Lope de Vega.

\section{ABstract}

This article discusses the lack -and need- of digital critical editions in the field of Spanish Golden Age theater. In showing the advantages of digital over paper editions for certain works, depending on their textual transmission, the article proposes some methods for the dynamic and interactive display of genetic processes, for works which are preserved in different versions, or for works which present special annotation complexities. Other issues discussed in the paper include digital project research management, circulation and preservation of scientific results, easiness in the use and effectiveness of digital tools intended for large critical edition projects. As a conclusion, the essay suggests the urgent need of both digital critical editions and the development of more user-friendly languages and text-editing softwares.

Keywords: Critical Edition; research project management; digital humanities; textual cases; Lope de Vega. 
Lo que nos depara el futuro informático es todavía un misterio —al menos para mí-; pero lo que sí está claro es que ese futuro se irá construyendo en la medida y en el modelo de los sueños que seamos capaces de articular en estos primeros tiempos de «balbuceos» de nuevas modalidades textuales y de su transmisión en soportes informáticos o en la Red (J. M. Lucía Megías 2007/2009:1)

\section{EditAR CRÍTICA Y ELECTRÓNICAMENTE. LA REFLEXIÓN PREVIA: ¿QUÉ QUEREMOS?}

Orese ualquier proyecto de Humanidades Digitales y, en consecuencia, cualquier proyecto de Filología Digital debe pasar por una reflexión profunda sobre cuáles son los objetivos, los medios y los resultados esperados. ${ }^{1}$ Creo que esa reflexión, como dije en una reunión de nuestro grupo de investigación en la primavera de 2012, debe proponerse, en Filología Digital, incluso más allá de realidades preexistentes. Es bueno observar qué se hace, considerar qué se puede hacer y con qué medios, pero nosotros, en tanto que filólogos en esta unión con los informáticos, debemos plantearnos más bien, o también, qué desearíamos y qué se nos ocurre que se podría hacer. Debemos soñar y aspirar a convertir en realidades esos sueños si no es que descubrimos, con una mejor información, que esos sueños son ya realidades, algo que también puede suceder... lo mejor que podría suceder. Pero si esos sueños no son todavía realidades alcanzadas, y si hay dificultades técnicas para realizarlos, si son puras quimeras, deberemos llegar a dicha conclusión tras la conversación con los informáticos y humanistas digitales, así como con un esfuerzo en nuestra propia formación en el terreno; y, tras dicha conversación y dicho esfuerzo, buscar soluciones factibles y alternativas.

Me centraré en los deseos de nuestro grupo de investigación, o como mínimo de quien firma este artículo, al afrontar la edición de la obra dramática de Lope. ¿Qué quiere nuestro grupo de investigación, Prolope? ¿Cuál es la finalidad de la incursión en el terreno digital? ¿Almacenar, preservar, publicar, divulgar nuestras ediciones? Obsérvese que los verbos que he reunido no son sinónimos, y, sin

1 Aunque pueda parecer obviedad, prefiero declarar que dos personas de amplísima experiencia insistieron en este principio en el workshop «Digital Text/Genetic Document. Text Encoding Initiative and Genetic Edition» (3-7 de septiembre de 2012) organizado por la profesora Bénédicte Vauthier: Elena Pierazzo («antes de emprender proyectos conviene analizar bien y cerciorarse de que objetivos y resultados merecen el esfuerzo y podrán lograrse y alcanzarse con los medios disponibles y elegidos») y Alejandro Bía Platas (con el énfasis que puso en el diseño del flujo de trabajo en los proyectos de Humanidades Digitales). 
embargo, los diferentes matices que comportan podrían ser asumidos por un único proyecto electrónico. De hecho, me atrevo a avanzar, sería lo deseable.

Por otro lado... ¿queremos limitarnos a la utilización de software o lenguajes ya establecidos o estamos dispuestos a experimentar? ¿Queremos que la vertiente electrónica, la investigación en edición digital, se convierta en un fin más de nuestro equipo de investigación o queremos limitarnos a editar? Obsérvese que la que planteo es una pregunta honesta y para nada retórica y, ahora sí, una disyuntiva: tan loable y aceptable sería decidir que queremos centrarnos en la edición crítica sin investigar sobre estos nuevos medios e instrumentos para su realización como asumir ese reto. ¿Por qué es necesario plantearse esta disyuntiva? Porque parece inevitable pensar que la apuesta electrónica, en términos de esfuerzo y dedicación, es una apuesta seria, importante, que va a conllevar una enorme «fuerza de trabajo».

Y la otra pregunta que viene inmediatamente a la cabeza es si a día de hoy podemos seguir prescindiendo de muchas de las potencialidades que ofrece la herramienta informática. Porque, si entrar por esa vía va a implicar un gran esfuerzo, ¿no lo implica también prescindir de ella? Habrá que poner unos argumentos y otros en la balanza y sobre esa base tomar las decisiones oportunas. Tal vez pensemos que en Humanidades no son necesarias herramientas informáticas para llevar a cabo nuestras tareas. Desde luego, para muchas de las tareas que llevamos a cabo, no son necesarias. Y lo demuestran años de existencia de la disciplina. Pero ¿vamos a ser tan obtusos como para no asumir que, del mismo modo que auxilian vitalmente a otras ciencias, pueden auxiliar a la nuestra?

Sea como fuere, lo que en estas páginas pretendo plantear es eso, ¿qué queremos? Para poder responder a esa pregunta, para establecer bien nuestros objetivos, será necesario exponer cuáles son los objetos de trabajo de ProLOPE, cuáles y cómo son nuestras ediciones, cuáles y cómo podrían ser nuestras ediciones electrónicas. Así podremos llegar a más sólidas conclusiones sobre si, cuándo, cómo, y con qué medios, nos conviene afrontar el camino de la edición crítica digital.

Empezaré por enmarcar en nuestro proyecto de investigación las ediciones electrónicas que por ahora nos estamos planteando, qué obras y por qué pensamos que para ellas la mejor solución es la edición electrónica. 


\section{NuESTRO CORPUS O NUESTROS CORPORA DE OBRAS Y EDICIONES ELECTRÓNICAS}

Como ya hemos anunciado en algún otro lugar y ocasión, ${ }^{2}$ aunque el proyecto del grupo Prolope sigue siendo la edición en papel de las Comedias de Lope tal como aparecieron en las sucesivas Partes de comedias, y hay para ello muy sólidas razones ecdóticas en el modo de proceder (es decir, el hecho de tomar como base para la edición esas Partes de comedias, que fue donde se transmitieron la mayoría de estas), nos queda un corpus, o mejor, varios corpora, por atender para alcanzar nuestro último objetivo: la edición crítica del teatro completo del Fénix de los ingenios.

El proyecto de edición de las comedias de Lope, dirigido por Alberto Blecua, ha adquirido ya entidad e identidad constituyéndose en un referente nacional, si no internacional, en la edición de teatro del Siglo de Oro (tal vez incluso en edición de textos del Siglo de Oro), como no podía ser de otra manera encabezándolo quien lo encabeza. Dicho proyecto sigue en marcha y en principio se seguirá desarrollando para su publicación en papel. Pero como en el proyecto original y principal se tomaban como base las comedias que se publicaron en las Partes de comedias, en el programa de trabajo quedaban por tanto postergados, de entrada, los autos sacramentales de Lope y todas aquellas comedias que no se recogieron en dichas colecciones (las podríamos llamar «sueltas», aunque sin relación necesaria con el sentido que a la voz «suelta» se le da en nuestra bibliografía material; otro posible término sería comedias «exentas»). Estos serían posibles grupos de piezas o corpora destinados a la edición digital, por razones meramente prácticas. ${ }^{3}$ Para otras obras podríamos aducir, además, razones científicas en nuestra preferencia por una edición digital. Parece oportuno, en el terreno digital, dedicarles una especial atención a los manuscritos autógrafos. A medio camino entre la crítica textual, la filología de

2 Véase A. García Reidy, G. Pontón y R. Valdés [2013:11-12]. Tuve ocasión de exponer los proyectos digitales de Prolope en Berna, en el workshop ya mencionado, organizado por la profesora Bénédicte Vauthier, así como en Bolonia, en el encuentro «Teatro Classico Spagnolo e Text Encoding Initiative (TEI)», organizado por Marco Presotto el 28 de septiembre de 2012, y en Elche, el 29 y 30 de noviembre de 2012, en las «Jornadas de Humanidades Digitales» organizadas por Alejandro Bía Platas. Algunas de las ideas que ofrezco en este artículo fueron también expuestas en esos foros.

3 No debe tomarse esto como un compromiso editorial de Prolope: no quiero decir aquí que asumamos ya la obligación de enfrentarnos a esas obras y por el medio digital. Solo quiero decir que ahí encontramos obras que por el momento han quedado fuera de nuestro proyecto principal por razones ecdóticas a la vez que prácticas y que podríamos editar electrónicamente. Sin embargo, parece que ya el grupo GRISO va a ponerse manos a la obra con los autos sacramentales de Lope, por ejemplo. Tal vez colaboremos con ellos o tal vez renunciemos nosotros entonces a su publicación, ya sea electrónica o no. 
autor (e incluso la crítica genética), estos documentos revisten un particular interés y necesidades diversas de tratamiento editorial. Por último, se nos ocurre que hay algunas obras, independientemente de que también fueran recogidas en las Partes, que podrían ser, por sus peculiares problemas de transmisión o necesidades de anotación, candidatas perfectas para una edición electrónica. El resultado de edición podría ser mejor que el que se pueda obtener en una edición en papel. En seguida entraremos en detalles.

Este sería el corpus, o estos serían los corpora de obras para los que por ahora podríamos proponer una edición crítica digital. Esto, independientemente de que para el corpus del teatro completo, incluido el que originalmente vamos publicando en papel, pueda llegar un momento en que consideremos oportuna su edición digital o su digitalización (casi seguro que así será). ${ }^{4}$ Aunque aquí sería necesario distinguir entre ediciones críticas concebidas para la publicación en papel y luego digitalizadas (posibilidad que contemplamos), ediciones digitales no críticas y ediciones críticas concebidas desde su origen como ediciones críticas digitales («born-digital»). ${ }^{5}$

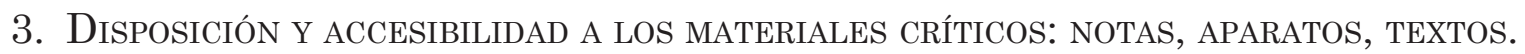

Problemas DE EDICIÓN Y SOLUCiONES DigitAles

Sin duda, una de las grandes ventajas que una edición electrónica puede ofrecer sobre una edición en papel es la de la acumulación y disposición más adecuada de los materiales de edición y anotación. Hasta no hace mucho, y desde sus orígenes, el grupo Prolope ofrecía toda la anotación de la obra al final del texto. La decisión respondía a un criterio: el lector al que se dirigen nuestras ediciones es un lector ya formado, que no requiere de una aclaración constante y que puede entender por sus medios y conocimientos el texto, y solo necesitará auxilio puntual. El editor, por otro lado, cuenta con la libertad de poder extenderse más o menos según la necesidad de anotación. Sin embargo, es cierto que esa colocación final implicaba mayor incomodidad para la consulta. De hecho, hay que pensar que incluso al lector

4 Sobre esta posibilidad, véase también lo dicho por Paul Spence en este mismo número, p. 66.

5 Como se verá más adelante, habrá que distinguir entre texto crítico y edición crítica: podríamos muy bien proponernos ofrecer textos críticos electrónicos: más problemático, por razón de derechos editoriales, resulta ofrecer la edición crítica digital si hablamos de nuestro proyecto principal, las comedias transmitidas por las Partes. 
especializado se le podían escapar algunos detalles de la obra. Como queríamos ofrecer un texto lo más limpio posible tipográficamente, y no había llamada de nota en el texto (el método de referencia era únicamente el número de verso), las notas quedaban "perdidas», «ignoradas», no había constancia de ellas y el lector no sabía qué se había anotado o no, de modo que a la incomodidad de pasar de un lado a otro del volumen en busca de la nota que ahí estaba, se añadía la de la búsqueda y frustración cuando ni siquiera estaba. En fin, esta fue la razón por la que, en 2010, decidimos anotar al pie. Desventaja de esta decisión: los límites de extensión de la nota por necesidades de maquetación. Aunque no está mal limitar a veces a anotadores prolijos y compulsivos, también es cierto que en ocasiones los materiales de anotación necesarios y oportunos son extensos e irreductibles. Vamos a ver un ejemplo concreto y que se entenderá enseguida. Hay que partir de la base de que el lector de una edición debe tener a su alcance todo el material para la intelección cabal de la obra.

En la Parte $X$ de las comedias de Lope de Vega había dos comedias que requerían el cotejo del texto dramático con la fuente documental utilizada por el poeta. Se trataba de las comedias El blasón de los Chaves de Villalba y Juan de Dios y Antón Martín. El editor de la primera, José Javier Rodríguez [2010:1195], se ocupó de realizar un acopio de materiales cronísticos que relataban los hechos presentados en la comedia. El editor de la segunda, Giuseppe Mazzocchi [2010:1369], se ocupó de cotejar diversos pasajes significativos del texto de la comedia hagiográfica con la Historia de la vida y sanctas obras de Juan de Dios, y de la institución de su orden, y principio de su hospital, de Francisco de Castro (Antonio de Librija, Granada, 1585). En ambos casos, para entender el proceso de documentación y de reescritura dramática era necesario aportar citas extensas y comparar las distintas fuentes. De este modo, se optó por incluir para ambas comedias un apéndice con estos materiales que habrían sido inasumibles a pie de página, dado que habrían ocupado la plana completa y ahogado el texto. ${ }^{6}$

No es necesario decir que la edición electrónica está libre de estas limitaciones de la edición en papel y de la disposición de la página. La edición electrónica

6 Véase la edición de José Javier Rodríguez, pp. 1345-1351, y la de Mazzocchi en colaboración con J. E. López Martínez, pp. 1501-1504. Una solución similar habría sido adecuada para La octava maravilla, en la misma Parte; en esta comedia se debía cotejar el texto con la crónica de los jerónimos de fray Jerónimo de Sigüenza, obra que Lope versifica, aunque pudimos valernos de un artículo ya publicado para remitir a él. 
puede ofrecer a su lector fácilmente un nivel de anotación básico y otro más profundo, ambos con igual comodidad para la consulta. Las notas se pueden hacer visibles y al final de las mismas puede aparecer un símbolo de adición (+) que ofrece la posibilidad de «leer más» a voluntad del lector. Todos los debates que manteníamos en Prolope se miran bajo una nueva luz: la elegancia tipográfica y de maquetación es compatible en la edición digital con la comodidad de consulta y la profundidad en la anotación. Incluso podríamos ofrecer textos completamente limpios desde el punto de vista tipográfico, desnudos, para el lector especialista y formado (que asumimos es el que va a leer muchas de nuestras ediciones) y anotados para el menos formado. En una edición interactiva, el lector puede elegir activar o no la opción de las notas, o incluso la profundidad de las mismas. ${ }^{7}$ Un ligero cambio de tono o intensidad en el color de la palabra en el texto nos podría señalar que esa palabra está anotada, y al pulsar o pasar el cursor sobre ella, abrirse automáticamente la ventana con la nota, que podría dar paso a su vez a otra nota más extensa si fuera necesario. Desde luego, en un concepto de plataforma editorial se podrían ofrecer las fuentes documentales en edición completa o en reproducción digital facsimilar, aunque entendemos que esta posibilidad no exime al editor de su obligación de seleccionar (y tal vez editar) los pasajes que conviene cotejar (véase al propósito Morrás 2003:229-230). En este sentido, cabe advertir que el editor no debe asumir la tarea de recopilador de materiales que puede ofrecer en hiperenlaces, lo que daría como resultado una hiperedición, sino que debe asumir la responsabilidad y realizar la tarea de seleccionar aquello que es directamente útil para entender la obra y el lugar que está anotando. El concepto de hiperedición y el uso de los hiperenlaces pueden ser muy útiles cuando se nos da acceso a materiales nuevos que no podemos acumular en nuestra propia edición por problemas prácticos de almacenamiento de la información, pero el editor debe seleccionar cuidadosamente esos enlaces (también en función de su previsible estabilidad y perennidad) y no desviar a ellos si no es estrictamente necesario. ${ }^{8}$

7 J. M. Lucía Megías [2007/2009:31] considera «dos de los criterios que más se han de desarrollar en los próximos modelos editoriales hipertextuales en el futuro: la interactividad y la personalización, ya que no se trata tanto de ofrecer resultados únicos — por más que la cantidad y variedad de los mismos sean realmente apabullantes-, como que cada usuario pueda utilizarlos según sus necesidades, según los criterios que considere más adecuados — más personalizados-para sus necesidades científicas» (insiste en la idea y la desarrolla en p. 49).

8 Véase el imprescindible J. M. Lucía Megías [2007/2009], que también propone un interesante concepto de «espacio de conocimiento». 
Hasta aquí se han observado ciertas ventajas de la edición electrónica sobre la edición papel para la anotación. Vamos ahora a cuestiones de texto y aparato crítico.

Nos centraremos de nuevo en problemas de edición ya experimentados, casos que se han presentado a lo largo de la historia editorial de Prolope. Expondré una serie de casos en los que creo que habría sido o sería mejor realizar una edición electrónica y, por tanto, casos en los que la presentación en papel implica una limitación, una renuncia a la inclusión de ciertos materiales, a la presentación de opciones editoriales igualmente válidas, o una presentación más incómoda y difícil de entender de ciertas informaciones textuales.

Cuando edité La batalla del honor para la Parte VI, una comedia con manuscrito autógrafo, tras hablarlo con el coordinador, que era Gonzalo Pontón, decidimos que la mejor manera de presentar todas las intervenciones de Lope de Vega in itinere en su propio manuscrito, con distintos tipos de interesantísimos pentimenti y reelaboraciones (supresiones, adiciones, descartes, etc.), sería en un apéndice, una especie de aparato crítico suplementario del manuscrito autógrafo independiente del aparato crítico de la obra, donde se recogían las lecturas definitivas del autógrafo acompañadas de las lecturas del resto de testimonios impresos. Qué duda cabe, hubiera sido mejor fundir ambos aparatos, pues así se podían entender mejor también algunas variantes, por pocas que fueran, de la tradición. Sin embargo, eso habría producido la hipertrofia del aparato crítico, así que, de las soluciones posibles, elegimos la que nos pareció menos mala: ese apéndice. Esas limitaciones desaparecen en el ámbito electrónico y ahí se podrían encontrar soluciones no menos malas, sino precisamente las idóneas. De nuevo en una concepción interactiva de edición, el lector puede crear un aparato crítico donde seleccione qué testimonios y variantes desea visualizar, incluidos los pentimenti del autógrafo y, así, relacionar todos los datos, las lecturas (más adelante ofreceré ejemplos con propuestas concretas). En este ámbito de la «filología de autor» y la crítica genética, las variantes del propio Lope en sus autógrafos, también tiene mucho interés lo que sucedió en el final de El castigo sin venganza. Ya nos hemos ocupado de ello en un artículo de carácter divulgativo. ${ }^{9}$ Es muy difícil plasmar en un aparato crítico inteligible (incluso para el especialista) todo el proceso creativo. Se puede hacer un relato de ello en varias páginas, tal como hicimos en ese artículo,

9 Véase Prolope [2011:251-272]. Preparo en estos días un artículo donde retomo y amplío lo expuesto allí para las Jornadas de Teatro Clásico de Almagro. 
o bien en un estudio textual que se ponga como prólogo a la obra. Sin embargo, aquí de nuevo, pensamos que la mejor solución es informática. En esta ocasión, el carácter dinámico del proceso, entiendo, aconsejaría una presentación dinámica que rebasa con mucho las capacidades del papel y que explota en profundidad las posibilidades de la edición electrónica de textos o documentos. Lo expondré a continuación; por ahora solo quería aludir a ello y pasar a ocuparme de otros problemas de transmisión donde la presentación ideal es la digital.

Más allá de las variantes de autor en el proceso de composición de su obra que acabamos de ver, hay otros materiales y variantes de sumo interés para las que considero mejor solución la informática. Ocurre así, sin duda, con los llamados "textos-variante» o versiones de una misma obra, ya sea de autor o no. En la tradición de textos teatrales de nuestro Siglo de Oro hemos de contar además con la intervención de otros agentes fundamentales: el autor de comedias y la censura. Vamos a ver un par de casos.

El hombre de bien, comedia incluida también en la Sexta parte de comedias, planteaba en su aparato crítico un problema muy similar al de los casos de anotación que hemos visto hasta ahora. Se transmitió en tres ediciones distintas: Madrid, 1615 (Viuda de Alonso Martín); Barcelona, 1616 (Sebastián de Cormellas), y Madrid, 1616 (Juan de la Cuesta). El antígrafo de la primera edición muy probablemente fue una copia muy deturpada de autor de comedias (incluso podría haber de por medio algún memorión), y en cambio el de la tercera casi con seguridad fue el propio autógrafo o bien una copia cercana a él. Eso genera un gran número de variantes y, de ellas, algunas de gran extensión. De la misma manera que nos encontramos a veces con la necesidad de poner notas demasiado extensas para una adecuada composición tipográfica de la página, nos encontramos a veces (como es el caso) con variantes excesivamente largas para una cómoda y mínimamente elegante presentación del aparato crítico. De hecho, en la transmisión de El hombre de bien se generan lo que su editora, María José Borja, llamó variantes-pasaje. Esas variantes-pasaje (que decidió serían las de más de seis versos) se vio obligada a consignarlas en un apéndice especial. En una edición electrónica todas las variantes podrían colocarse en el mismo aparato crítico o en el mismo lugar, y presentar sólo cinco líneas de las más extensas colocando al final un signo de adición que abriría una nueva ventana sin perder nunca de vista algo esencial: el texto (contexto de la variante) ni el resto de lecciones que rodean el lugar crítico. Creo que no hay discusión posible: la solución digital es mejor. 
Veamos otro caso. La bella malmaridada nos llega, según nos explica su editor, Enric Querol Coll [1998:1181], «por dos tradiciones textuales muy diferentes: la impresa [en la Segunda parte de las comedias] por medio de seis ediciones antiguas entre 1609 y 1618, y la copia manuscrita realizada por Ignacio de Gálvez en 1762 sobre unos autógrafos que probablemente se hallaban en el archivo del duque de Sessa». Se trata, por tanto, de un manuscrito apógrafo de gran fiabilidad, como todos los de la colección Gálvez.

El manuscrito contiene, al final, la transcripción de algunos pasajes que fueron censurados.

Son seis pasajes, de los cuales el último, sexto, está integrado en el texto, rayado y censurado explícitamente por Gracián Dantisco; los fragmentos 1 a 5 fueron copiados, añadidos, al final del manuscrito y con señales de remisión al lugar que debían ocupar en el texto.

En cuanto a la tradición impresa, incluye dislocaciones de estrofas y escenas, «autocensura» de pasajes eróticos e incluso sacrílegos (por ejemplo, un pasaje erótico con connotaciones religiosas en relación con el agua bendita), resumen o acortamiento de escenas, y supresión de algún pasaje de hasta 379 versos (el más importante, con una retahíla de cosméticos y ungüentos celestinescos). Ninguno de los pasajes afectados «cambia en su esencia el desarrollo argumental ni la psicología de los personajes» (p. 1184), aunque los tintes hagiográficos de Lisbella y la consecuente aparición del marido como verdugo cegado por el vicio, o la dimensión sobrenatural, desaparecen en los impresos. Todos los pasajes eran susceptibles de levantar ampollas entre los moralistas.

La tradición impresa no recoge ninguno de los pasajes censurados por Gracián Dantisco y también elimina algún otro que pudiera resultar reprensible. «Las numerosas variantes textuales, además, permiten hablar de dos versiones del texto. La segunda (rama impresa) resultaría de la adaptación hecha por un autor de comedias» (Querol Coll 1998:1185). Podría tratarse de Nicolás de los Ríos, que seguramente representó la obra en Granada: por ello, su manuscrito, según Querol, debería acarrear las censuras del censor granadino, así como las modificaciones escenográficas que quisiera hacer. «Esa versión censurada y modificada —o la de otro representante, siguiendo el mismo procedimiento - es la que llegaría a la imprenta de Madrid a finales de 1609» (ibidem).

La opción editorial de Querol fue la más adecuada en una publicación en papel, pero hoy tenemos otras soluciones a nuestro alcance. Dada la trascendencia de las 
variantes, su importancia cualitativa y cuantitativa, Querol editó $M$ por un lado y los impresos por otro. Así pues, editó los dos estadios de transmisión por separado y por lo tanto... sin relacionarlos «en sistema». Hizo una edición crítica del manuscrito teniendo en cuenta las ediciones modernas, y una edición crítica de los impresos con el aparato crítico de su tradición, pero sin reflejar las lecturas y divergencias de $M$, es decir, del testimonio que se puede considerar más cercano al original perdido y que, a fin de cuentas, generó esa misma tradición impresa. No es por tanto una edición crítica de la obra, sino la edición de dos hitos en la transmisión de la misma, más bien se trata de dos ediciones históricas. Diríamos, por tanto, que en rigor no es tanto una edición crítica cuanto la edición histórica de dos textos. ${ }^{10}$ De hecho, a consecuencia de este modo de proceder, se produce alguna incongruencia. Así, por ejemplo, el verso 1051 se enmienda a partir de $M$ en el texto crítico de la tradición impresa, pero no queda reflejado en el aparato crítico (aunque sí es advertido en la introducción). Ese es un caso, pero hay más que no son anunciados, y que solo podremos saber si volvemos a realizar un cotejo de la obra.

Ciertamente, en la solución papel el único modo de ofrecer textos críticos si se editan versiones es incluir el aparato crítico completo en cada uno de los textos variante generados. Sin embargo, por lo general, se considera reiterativo hacerlo y se opta por recoger el aparato crítico en uno solo de dichos textos, llamémoslo versión $\mathrm{A} \cdot{ }^{11} \mathrm{Al}$ actuar así, al potencial lector de la versión $\mathrm{B}$, a la que en principio se le otorga igual valor textual, dado que se publica también, se le deja sin apoyatura para entender el texto y las variantes de la obra, es decir, los datos en el sistema. Hay, pues, una deriva indeseada pero inevitable: a pesar de que en esta situación A y B se consideran versiones que deben ser respetadas en términos de paridad, al final aquella que se elige para proporcionar el aparato crítico será la leída y la inevitablemente «canonizada». A la vista de todo lo dicho, de nuevo, por cuestiones de espacio y por cuestiones de ahorro de fuerza de trabajo, tanto del editor como del lector, la solución informática será la mejor. Voy a mencionar sólo un caso más al que ProLOPE se está enfrentando en este mismo momento, en la Parte XV, La encomienda bien guardada o La buena guarda.

10 Para estos conceptos, y la conveniencia de distinguir géneros de edición (crítica versus histórica) véase Giunta [1997] y Valdés [2012], y recuérdese que la suma de sucesivas ediciones históricas no da por resultado una edición crítica; o, por formularlo de otro modo aquí pertinente: la sucesión de dos textos históricos no producen un texto crítico, por cuidada y rigurosa que sea la edición.

11 En la tradición textual de Calderón los problemas de las versiones son recurrentes. La solución que habitualmente se adopta es la que aquí he referido: elegir exclusivamente uno de los textos para ofrecer el aparato crítico. 
El testimonio más importante que conserva La buena guarda y La encomienda bien guardada es un manuscrito autógrafo que se halla en la Biblioteca Nacional. Los diferentes estratos de intervención que se encuentran en el mismo manuscrito, como veremos, hacen extremamente difícil una buena solución editorial ya no solo desde un punto de vista práctico, sino incluso teórico.

El texto autógrafo de La buena guarda (primer título de la obra) presenta las habituales variantes autoriales in itinere en los autógrafos de Lope. Sin embargo se produce algo muy peculiar: acabada la primera redacción de la obra titulada $L a$ buena guarda, en un segundo momento (cabe pensar que muy cercano al primero, es decir, muy poco después de finalizar su escritura) el poeta tacha más palabras y pasajes e incluye una serie de cambios que son sistemáticos y que proponen una segunda versión, casi podríamos decir, una nueva obra, una refundición: La encomienda bien guardada. Sustituye de manera sistemática toda alusión a la condición religiosa de la protagonista en el texto original por opciones más laicas en el texto refundido y cambia asimismo cualquier alusión a una geografía española concreta (más asociada a la leyenda religiosa) por una geografía italiana (menos connotada). Es por ello que Stefania Capoia habla prácticamente de dos textos recogidos en un único manuscrito. ${ }^{12}$

En el manuscrito se hallan, pues, dos estratos que presentan dos textos, dos obras, y que se deben, ambos, al poeta. Pero hay más estratos todavía. Encontramos también la intervención de la mano del autor de comedias: hace las intervenciones típicas de su oficio (por razones escénicas, acortamiento del texto, simplificación de tramas), pero, además acaba de hacer las correcciones que a Lope se le habían escapado en la labor de laicización o de «relocalización» del texto original.

Si La encomienda bien guardada se puede considerar la versión definitiva y no producto de presiones censorias, como dice Stefania Capoia, es correcto optar por editarla frente a la tradición editorial asentada hasta entonces, que recuperaba el primer texto, La buena guarda. Sin embargo, al prestigioso calificativo de «definitiva» que hace valer Capoia podríamos oponer el de "primigenia»... Sin duda, la redacción de La buena guarda fue la más genuina y libre, y la primera en la intención del autor. Aunque fuera labor de autocensura, incluso sin recibir presiones directas en este caso concreto (cosa que no sabemos), ¿se puede garantizar que en la España

12 Para mayor detalle en el aspecto puramente filológico, véase el artículo de Stefania Capoia que recogemos en este mismo número. 
inquisitorial de la Contrarreforma un poeta hiciera un acto así «libre de presiones»? Sabemos que había recibido una censura negativa en una comedia hagiográfica previa. Aunque cada editor ha ofrecido sus razones y las ha hecho valer, encuentro, a decir verdad, razones para editar los dos textos otorgándoles igual valor.

El caso textual de La buena guarda y La encomienda bien guardada es tan apasionante por todas las peripecias por las que pasa, las manos y estratos que en el manuscrito hay reflejados, que ¿no merecería ser editado con toda la riqueza que aportan sus diferentes manos? Me parece obvio que el mejor modo de reflejar, identificar y hacer entender todos los agentes que hay en ese manuscrito es a través de una edición electrónica interactiva que nos permitiera seleccionar versiones u obras, manos, aparatos críticos. Estaríamos en el caso de un manuscrito con dos obras, o bien una obra con dos versiones, si se quiere. Pero incluso entonces, en la segunda de esas versiones, será conveniente dejar claro, como ocurre en ciertas intervenciones arqueológicas, ver cuándo quien retoca y corrige la obra es el propio poeta, y cuándo es el autor de comedias que acaba de realizar la corrección que estaba en el ánimo del dramaturgo. También, por mucho que sea intrascendente para la constitutio textus, será fundamental en cambio para entender la historia de la representación, tener a la vista todas las intervenciones del autor de comedias relativas a su oficio en su contexto, es decir, en el propio texto: cómo lo retocaba, qué abreviaba, qué le planteaba problemas escénicos... Bastaría con elegir una opción: intervenciones del autor de comedias (previamente habrían sido introducidas bajo dicha categoría) y resultarían destacadas tal vez con un determinado color, por proponer una solución.

De hecho, la presencia en este documento de la mano del autor de comedias nos invita a una reflexión ulterior. En el terreno de la edición electrónica tendríamos mayor facilidad para atender aspectos que han quedado desatendidos tradicionalmente en la edición del teatro del Siglo de Oro. Podríamos no solo recoger las intervenciones del autor de comedias, sino destacar todo lo que Christopher B. Balme [2008] llama el "texto secundario»: todas aquellas indicaciones que se encuentran en el texto para entender la puesta en escena (las didascalias, las acotaciones implícitas o explícitas y las propias anotaciones manuscritas del viejo autor de comedias). Esto se podría hacer en primera instancia o bien sería uno de los posibles desarrollos en trabajo colaborativo con otros investigadores, pero sea como sea, hemos de ser conscientes de que es tarea del editor intentar salvar 
todas las dificultades con las que se enfrenta el lector para entender cabalmente la obra literaria, que en este caso no es solo una obra literaria, es además obra y espectáculo teatral. ${ }^{13}$

\section{SuEÑos ELECTRÓNICOS: TRANSCRIPCIONES Y EDICIONES CRÍTICAS DIGITALES}

Hace tiempo que soñamos con las posibilidades de la edición digital. Esas posibilidades abarcan tanto las diferentes fases de la crítica textual como la propia edición crítica digital en cuanto producto final. O mejor, matizo: como hipótesis de trabajo, por volver a la clásica definición de Contini, o incluso, vuelvo a matizar sobre el matiz, como trabajo perpetuamente in fieri. Esa idea de la fluidez de la edición crítica tiene una fuerte relación con las posibilidades del nuevo medio digital, por mucho que crea que, con todo, el editor crítico debe ofrecer al lector medio (y también debe proponer y defender ante el investigador) un texto fijo. Hasta cierto punto, el planteamiento de Contini de la edición crítica qua hipótesis no deja de ser paradójico, contradictorio con una de las fases de la crítica textual, a la que finalmente aspira: la fijación de un texto. Estas reflexiones no son puramente teóricas. Pueden tener consecuencias prácticas y sobre todo en el medio digital. ${ }^{14}$

Voy a centrarme, pues, en primer lugar, en la edición crítica digital como producto. ¿Cómo querría yo que fuera el aspecto de una edición crítica publicada en web? La maleabilidad de la pantalla, la interactividad del lector con el producto, pueden hacer de la edición digital algo mucho más interesante y de lectura mucho más clara (diría incluso intuitiva) que una edición crítica en papel. José Manuel Lucía Megías [2007/2009:16] aludía hace unos pocos años al «incunable» de la era digital, como si todavía estuviéramos en una fase en la que, efectivamente, no le sacamos todo el partido al nuevo medio del que disponemos. Creo que así seguimos en muchos aspectos. Por ejemplo, en el terreno de las revistas digitales se diseña

13 Véanse a este propósito las sugerentes reflexiones de Christopher B. Balme [2008:118-131], el capítulo que titula «Text and Performance». Jonathan Thacker ha llamado reiteradamente la atención sobre esta deficiencia en la aproximación histórica y editorial al texto / hecho teatral por parte de la crítica española. Son temas de los que se ha ocupado también Profeti, por ejemplo en [1996].

14 Para el debate entre las distintas posiciones teóricas y las posibilidades de realización de algunas de ellas en el medio digital, véase Morrás [2003:27-29; concretamente, sobre la superioridad de las posibilidades del soporte digital sobre el soporte papel: p. 28]. 
una plataforma de servicios como el Open Journal System en el que los especialistas aconsejan atenerse al formato estático y bidimensional del pdf. Son difíciles por ahora las animaciones o contenidos multimedia. Fijémonos en un detalle que puede parecer menor, pero que considero sintomático del apego a los viejos formatos: esas páginas se suelen diseñar, como la que el lector ahora está leyendo, en DIN-A4 vertical, cuando las pantallas para las que se concibe su uso recomendarían la disposición horizontal. Es decir, seguimos las inercias de un formato, caja y mancha de tinta de papel, si se me permite la metáfora. Pero volvamos a lo que nos interesa, las ediciones críticas digitales. ${ }^{15}$

No quiero perder el tiempo en lo que «no debe ser». Vamos directos a lo que «debe ser» o "querría que fuese». Voy a tratar de definir dos productos que básicamente son los que creo que interesan a nuestro grupo de investigación. La edición crítica tradicional, con un aparato de variantes, de notas y de diferentes informaciones que normalmente ofrece Prolope para las comedias del Fénix de los ingenios, y por otro, la transcripción de los manuscritos autógrafos con toda la riqueza informativa sobre el proceso de creación. Empezaré por los últimos, aunque sobre estos quien lleva la voz cantante es Marco Presotto, que en estos momentos ya está elaborando una transcripción TEI de La dama boba que servirá de ensayo y tal vez de modelo para posteriores trabajos (su artículo aparecerá en el próximo número de esta revista). ${ }^{16}$ Debo aclarar aquí que cuando, en el seno de nuestro grupo, discutimos sobre los objetivos de ambos tipos de edición, ambos productos, se decidió que la transcripción del manuscrito autógrafo debía ir orientada a la divulgación de la manera de trabajar de Lope y de nuestra tarea como editores. Ese aspecto divulgativo comporta, a nuestro modo de entender (coincidíamos todos), la obligación de ofrecer un producto fácilmente inteligible por cualquier público, obviamente no especialista, y un cierto grado de espectacularidad.

Esos objetivos principales sería deseable que fueran compatibles con un avance científico real. El producto no debería tener solo interés para el público

15 Véase en este mismo sentido la afirmación de Paul Spence (pp. 49 y 62) en este mismo número.

16 La Iniciativa de Codificación de Textos (Text Encoding Initiative: TEI) surgió del trabajo conjunto de humanistas e ingenieros que valoraron la necesidad de desarrollar un lenguaje de codificación específico para materias humanísticas a partir de SGML y luego del XML, útiles tanto para bases de datos como para editores de texto, hojas de cálculo, etc. Para una descripción mínima y muy concreta de lo que implica el lenguaje TEI en nuestro trabajo véase la nota 28 y J. T. Nogales Flores [2002/2006]. 
general, sino también para el especialista. ${ }^{17}$ En esa medida, el esfuerzo de trabajo tiene una doble justificación. La mera digitalización del texto es ya un avance científico apreciable. Creo en la legitimidad y compatibilidad de ambos objetivos. Pero es que además, en cualquier caso, y sea como fuere, creo que incluso desde un punto de vista puramente científico es más provechoso y eficiente una presentación más intuitiva y clara, de modo que también ese carácter "divulgativo» va a redundar en un beneficio científico. Este principio vale para varios de los argumentos y soluciones informáticas que voy a exponer.

$\mathrm{Si}$, cuando nos enfrentamos a la transcripción o edición de las variantes del manuscrito autógrafo, lo que queremos reflejar es el texto en su proceso creativo, nos conviene una presentación dinámica para conseguirlo. ${ }^{18}$ No sé qué programas conviene utilizar ni cómo se puede crear la hoja de estilo, el output de los datos introducidos, ${ }^{19}$ pero sí tengo una idea de la visualización que busco. Es algo que deberá surgir de la colaboración activa entre filólogos e informáticos o de filólogos adecuadamente formados, es decir, humanistas digitales. Yo diría que lo que más se parece a eso que yo imagino lo he visto y soy capaz de bocetarlo, por mí mismo, en algo tan básico como el programa PowerPoint de Microsoft. ${ }^{20}$ La presentación del texto, por supuesto, implica una interpretación filológica: interpretamos, por ejemplo, que Lope intentó escribir una "tirada» de tres versos, y es al escribir el tercero cuando se arrepiente, tacha, recomienza y los reescribe (pulse aquí: +). ${ }^{21}$ Es decir, no escribe uno, y lo tacha, y lo vuelve a escribir, y lo tacha así hasta tres veces. Lo podemos suponer

17 Así sentencia J. M. Lucía Megías [2007/2009:9-10]: «Uno de los principios de la Informática textual: no es incompatible divulgación con ciencia. Todo lo contrario. Entre los criterios de comparación entre los distintos medios de transmisión, Internet sobresale por tres, frente a los medios analógicos y a los discos ópticos (CD-Rom y DVD): actualización, densidad y recuperabilidad».

18 Lo que propongo no tiene nada que ver con el uso de presentaciones en vídeo de la exposición virtual sobre Brouillons d'ecrivain en la Biblioteca Nacional de Francia, sección «Fabrique du texte», «Corriger», «Balzac, La femme superieure». El vídeo que yo propongo cumpliría la función de análisis de las variantes, no presentación genérica del manuscrito, que es lo que allí vemos.

19 Aclaración para legos: input, entrada del texto que es tecleado con los códigos necesarios para su posterior lectura por la hoja de estilo; output, que podrá visualizar el usuario, el lector.

20 Seré sincero: ni a eso llego. Debo dar las gracias a Celia Sales Valdés por su ayuda en la preparación de ese ppt.

21 Pido perdón, o mejor, explico el porqué de lo que podría parecer carácter diletante de mi exposición. Responde a un concepto muy claro de Humanismo digital, en el que el filólogo no tiene por qué dominar las soluciones técnicas informáticas, sino plasmar sus ideas del modo más claro posible y buscar, codo a codo con el ingeniero, la solución técnica. De hecho, podría decirse que lo que aquí se ofrecen son algo así como anteproyectos o bocetos de lo que se quiere conseguir. Sigo, en esto, el consejo de Paul Spence. 
porque hay una continuidad de sentido, aunque también podría darse ese otro caso, que requeriría una presentación distinta. Seguramente un input o marcaje distinto y tal vez también un output u hoja de estilo distintos. En el caso que hemos visto el pentimento y la corrección se producen en el momento de la primera escritura.

También podría pasar que en un segundo momento, de revisión, el poeta corrigiera, como habitualmente solía hacer, añadiendo algunos versos en el margen. Requeriría una representación y marcaje distintos, así como una distinta visualización. En la visualización de la transcripción creo que sería también deseable que se nos ofreciera en un menú la posibilidad de tener:

1. Una presentación estática que permitiera ver, para su estudio, todos los tachados y reelaboraciones que se encuentran en el manuscrito, que habría que reproducir de una manera aproximada, aunque no me obsesionaría por que fuera fidelísima, sino tal vez esquemática, un croquis (pulse: + ) .

2. Una presentación dinámica que ofreciera al lector / espectador del texto una imagen del proceso mental y creativo del poeta $(+)$.

3. Una presentación estática final que permitiera leer la obra completa en su redacción definitiva $(+)$.

Entiendo que, idealmente, para economizar trabajo, con un solo input, y diferentes hojas de estilo, tal vez podrían obtenerse estos resultados, o resultados aproximados. Se han presentado solo un par de casos de problemas textuales, pero basta para hacerse una idea de lo que entendemos por presentación dinámica del aparato crítico de variantes de autor, internas, en un manuscrito autógrafo.

Dejemos ahora la transcripción del manuscrito autógrafo y vayamos a la edición crítica de una obra con diferentes testimonios y aparato crítico. El producto y los objetivos en principio son distintos (no necesariamente divulgativos), distinto el marcado y etiquetas si hablamos de lenguaje TEI, así como será distinto también el output o la visualización.

En este caso lo que más se aproxima a lo que siempre he imaginado, a pesar de haber visto ediciones críticas digitales con anterioridad, es algo que vi por primera vez en el congreso organizado por el grupo Artelope y celebrado en el mes de mayo de 2012 en Valencia sobre «Lope de Vega y el Teatro Clásico Español. Nuevas 
Estrategias de conocimiento en Humanidades». Jesús Tronch nos mostró un proyecto, Internet Shakespeare Editions, de la Universidad de Victoria, Canadá, que por muchos conceptos me parece ejemplar $(+)$. Uno de ellos, solo uno de ellos (lo digo por la riqueza y concepción de la web y del proyecto en general), es la presentación de sus ediciones y del aparato de variantes en ellas. Me parece mucho más logrado que otros proyectos digitales. La posibilidad de elegir los testimonios que se quieren visualizar o la presentación simultánea de las variantes con identificación a través de los colores de los distintos testimonios se aproxima mucho a lo que puede desear el filólogo que está realizando una edición crítica o quiere estudiar la transmisión de la obra. Recuérdense los consejos prácticos de Alberto Blecua [1983:45] sobre el uso de los colores para marcar e identificar las variantes de los distintos testimonios durante el penoso proceso de la collatio codicum. Ese trabajo, que era preparatorio para el objetivo final, la publicación en papel, quedaba abandonado en el despacho del filólogo y el siguiente editor debía comenzar desde cero; tanto el aparato de variantes como el texto deberían quedar ahora al alcance de la comunidad científica a través de una presentación así: almacenado en la web, e idealmente perenne e interoperativo. ${ }^{22}$ De hecho, esa presentación de las variantes constituye de por sí ya el aparato crítico tal como se puede publicar y que va a entender mejor cualquier lector. Sigamos con el aspecto que creo que deberían tener nuestras ediciones.

Con todo, se me ocurrirían varias mejoras partiendo del excelente proyecto Internet Shakespeare Editions. Creo que uno de los obstáculos que permite salvar la herramienta electrónica son esas notas que en una edición en papel estorban en exceso la lectura. El proyecto Internet Shakespeare Editions tiende a una anotación escueta para la que no veo razón. O no veo razón como criterio exclusivo. Así, creo que sería buena idea un doble nivel de anotación que se puede organizar como veníamos comentando en los ejemplos anteriores de Juan de Dios y Antón Martín o de El blasón de los Chaves de Villalba: en el ordenador resultaría extremadamente cómodo organizar y consultar tomando como ejemplo la famosa colección Biblioteca

$22 \mathrm{Ni}$ que decir tiene que hoy en día el resultado de una collatio codicum puede ser puesta al alcance de la comunidad científica: de hecho, en un espíritu colaborativo y de web 2.0, las diferentes fases de nuestra investigación pueden — deberían - quedar a disposición de todos y no ser necesario repetir determinadas operaciones, sino a modo de comprobación. Es como si en otra época un filólogo nos pasara sus apuntes para realizar la edición. En esta línea: Morrás [2003:230]; véase también Numerico, Fiormonte y Tomasi [2010:54-69]. Volveremos sobre esto un poco más adelante. 
Clásica concebida por Francisco Rico. Así, las notas, que serían breves en un primer nivel, podrían expandirse para poder profundizar todo lo necesario cualquier aspecto, tanto el editor como el lector que lo desee. Incluso podríamos plantearnos la posibilidad de un lector múltiple: elegir el nivel del lector y sobre esa base eliminar ciertas notas o secciones de ellas. Por ejemplo, es obvio que un lector especialista no va a necesitar una aclaración sobre la palabra «luego» con el sentido de 'inmediatamente'. Esa nota, a la hora de introducir datos, sería clasificada como nota para un lector básico y se podría ahorrar en la visualización ofrecida al especialista. Y viceversa; algunas notas podrán interesar solo al especialista y ser eliminadas para un lector no filólogo.

Pero volviendo a las cuestiones puramente textuales, hay otra situación que encontramos en algunas obras de Lope, que como antes decíamos en la edición en papel tienen mala solución y en cambio, en la edición electrónica, se me antoja buena y sencilla. Es responsabilidad del editor ofrecer un texto, el que llamamos «texto crítico». Constituir un texto partiendo de un texto base y la selección de las lecciones mejores de los distintos testimonios. Sin embargo, tropezamos con el problema de las versiones de autor, como hemos visto en el caso de La buena guarda / La encomienda bien guardada. El sistema que voy a proponer permitiría, teóricamente, visualizar a partir de un solo input cualquier versión, o incluso, si lo deseáramos, cualquier testimonio. Mi propuesta consiste en que el programa o la hoja de estilo elija automáticamente todas las variantes de la versión 1 o la versión 2 y las integre en el texto invariante.

Imaginemos que tenemos una obra con seis testimonios (A, B, C, D, E y F); de ellos, hay dos que constituyen "versiones», es decir, que contienen "variantes de autor» y constituyen "textos variante». La versión 1 es representada por el testimonio A y su rama (BCD), y la versión 2, supongamos, por el testimonio E y su rama $(\mathrm{F})$ :

Testimonio A (Versión 1) > Texto crítico 1

Testimonio B

Testimonio C

Testimonio D

Testimonio E (Versión 2) > Texto crítico 2

Testimonio F 
Pues al menos esos dos testimonios y versiones se ofrecerán en menú para constituir un texto. Hay que considerar por otro lado que, si llegamos a la conclusión de que las versiones 1 y 2 tienen igual autoridad, habremos de constituir sendos textos críticos, pues las propias variantes de la versión 1 y 2 pueden tener repercusiones en las lecciones que haya que elegir en otros lugares críticos y que no correspondan eventualmente ni a un testimonio ni a otro (para constituir el texto crítico de la versión 1 podemos necesitar acudir a lecciones de B, C o D y para el texto crítico de la versión 2 a lecciones de $\mathrm{F}$; o incluso, para cualquiera de ambos textos críticos, a cualquiera de los testimonios). Creo que es esencial que, si consideramos que las versiones 1 y 2 tienen igual autoridad, los textos de A y E merecen ser la base para la constitución de un texto crítico. Este podría ser el aspecto de la pantalla con las distintas opciones, inspirada en el concepto de Internet Shakespeare Editions pero desarrollada:

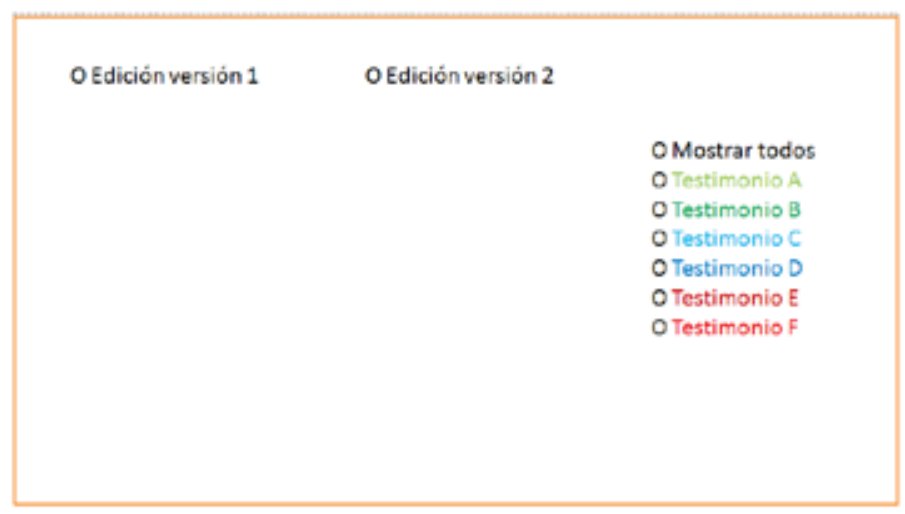

Por otro lado, cada uno de esos textos críticos debe generar su aparato crítico, es decir, su aparato propio y distinto de variantes.

\section{Aparatos críticos alternativos}

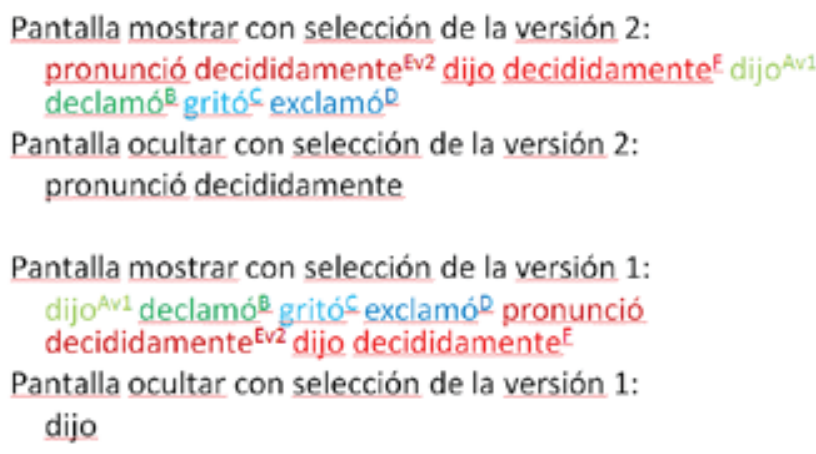

Pantalla mostrar con selección de la versión 1: dijo ${ }^{A v 1}$ declamó ${ }^{\mathrm{B}}$ gritó exclamó $^{\mathrm{D}}$ pronunció decididamente ${ }^{\mathrm{EV} 2}$ dijo decididamente $\mathrm{F}^{\mathrm{E}}$

Pantalla ocultar con selección de la versión 1: dijo 
Mi propuesta consiste en que si elegimos visualizar el texto crítico de la versión 1 , automáticamente las variantes de la versión 2 , y todos los testimonios, pasarían a integrarse en el aparato crítico, y viceversa, si elegimos la versión 2, las variantes de la versión 1 con el resto de testimonios, irían a integrarse en aparato crítico. Lo mismo ocurriría si deseáramos visualizar cualquier testimonio concreto. ${ }^{23}$ No sé si, como filólogos, somos conscientes de las consecuencias de esta posibilidad informática, si es que existe, y yo creo que sí. El concepto de texto base, a mi modo de ver, debe seguir existiendo, desde luego, quién lo duda, pero ya no condiciona de la misma manera el trabajo filológico. ${ }^{24}$

Volvamos un momento al proyecto Internet Shakespeare Editions para ver cómo se podría plantear, y tal vez mejorar, para dar cabida a los problemas de que venimos tratando. Si entramos en la edición de David Bevington de As you like it (+), observamos en la página inicial de la edición que se nos ofrecen dos textos de la obra: el folio de 1623 en edición histórica — podríamos llamarlo «transcripción», tal vez- y lo que se denomina el Texto Moderno, que vendría a ser el texto crítico. Pues bien, si entramos en la edición histórica del folio de 1623 observaremos que ni hay notas, ni aparato crítico, que solo están disponibles en el Texto Moderno. Por lo tanto, a mi modo de ver, no resolvería un caso con versiones como el que ahora estoy yo planteando. ${ }^{25}$ De hecho, esta solución es la misma que se viene ofreciendo tradicionalmente, como ya hemos dicho antes, cuando se edita «por versiones» en papel, supongo que para no incurrir en gastos o para evitar reiterar materiales ya presentados. Sin embargo, si leemos la versión sin aparato crítico no vamos a poder «relacionar los datos en el sistema» como pedía de una edición crítica Contini. Independientemente de que estas soluciones ecdóticas sean o no discutibles para esas obras, sin duda, es cierto, existen ocasiones en que no queda más remedio que hablar de versiones, y entonces la solución informática, desde ahora, habrá que considerar que es sin duda alguna la

23 ¿Qué utilidad puede tener visualizar la transcripción de cualquiera de los testimonios, incluso menos autorizados? Se me ocurre una respuesta rápida y bien sencilla: aunque solo fuera para comprobar la corrección de la transcripción le resultaría útil a algún investigador. O para filiar una traducción de la época, por poner otro ejemplo.

24 Nada tiene que ver lo que vengo diciendo con aquellos que celebraron, merced a la llegada del medio informático, el fin de la edición crítica (véase Morras 2003:228-229). Al contrario, vengo defendiendo a lo largo de estas páginas la necesidad de compromiso del editor con un texto; el problema de las versiones y ediciones históricas está relacionado, pero es distinto.

$25 \mathrm{Si}$ accedemos a otros textos que podrían afrontar el problema de las versiones, como Macbeth o Hamlet, por desgracia para ellos no se ha preparado el aparato de variantes (la opción «Variants» no aparece en la «Toolbox»). 
mejor. Partiendo del modelo de Shakespeare Internet editions, lo único que propongo es:

1. Que el cuadro de «Commentary Text» o «Toolbox» con las colaciones y las anotaciones esté permanentemente visible, tanto para una versión como para otra.

2. Que en la lista de textos o testimonios se incluya también el «texto crítico» o los «textos críticos» en el caso de haber más de uno.

3. Se podría añadir una utilidad que fuera de textos paralelos (edición sinóptica) también para el cotejo de dos o más versiones. ${ }^{26}$

4. De estos materiales textuales, algunos serían publicados para el lector medio, al que el editor está obligado a ofrecer un texto crítico. Sin embargo, otros textos y utilidades (la posibilidad de recuperar la transcripción de determinados testimonios) podrían estar disponibles solo para usuarios registrados.

5. Que, aparte de la edición del texto, en una sección de acceso restringido para el investigador registrado se pueda reconstruir cualquier testimonio sobre la base de las variantes introducidas. Esto valdría tanto para las obras con varias versiones como para las obras de una sola versión con múltiples testimonios.

El sistema que yo propongo nos permitiría reconstruir, en diferentes pantallas, cualquier testimonio, lo cual es especialmente interesante en el caso de las que llamamos ediciones históricas. La idea es que si hemos introducido una vez el texto y si introducimos correctamente todas las variantes, el juego entre el texto fijo o invariante (la cadena de palabras que aparece en los distintos testimonios y constituye sus textos) y las variantes de los distintos testimonios (las que varían dentro de esa cadena), nos permitirá reconstruir, a través de un solo input, diversos output o visualizaciones con los distintos textos y los respectivos aparatos críticos.

26 Podríamos entonces acudir a otro modelo, que podría ser el presentado por Juxta, para la Declaración de la Independencia de los Estados Unidos. 


\section{LA COMPATIBILIDAD Y OPTIMIZACIÓN DE LOS PROYECTOS: TRANSCRIPCIÓN DEL MANUSCRITO} AUTÓGRAFO Y EDICIÓN CRÍTICA. LA EXPLOTACIÓN DE LOS DATOS INTRODUCIDOS

Esto me lleva ahora a hacer unas consideraciones que creo que son necesarias en cualquier proyecto de investigación y tal vez más en proyectos de Humanidades Digitales, consideraciones en relación con el flujo y el aprovechamiento y optimización del esfuerzo de trabajo. Hasta ahora he hablado de la transcripción de los manuscritos autógrafos y de las ediciones digitales como dos objetivos y productos distintos, tal como fueron concebidos en reuniones de nuestro grupo de investigación. Creo que es necesario plantearlo así, en cierta medida, dados los objetivos didácticos, de publicación de resultados y, diría, casi de publicidad para la actividad del grupo y de espectacularidad del producto. Si lo que buscamos con la transcripción del manuscrito autógrafo es hacer llegar al público de cultura media el proceso creativo de Lope y plantearlo hasta cierto punto en términos de divulgación y transferencia de conocimiento a la sociedad, entonces efectivamente el output, la hoja de estilo, la visualización, ha de incluir esos elementos de espectacularidad que tal vez no sean tan útiles ni necesarios en el trabajo y el producto filológico y dirigido a filólogos. Sin embargo, estimo que, realizado el trabajo de transcripción del manuscrito autógrafo, de ninguna manera podemos desaprovechar ese input, ese esfuerzo, para su explotación más propiamente científica. ${ }^{27} \mathrm{Si}$, por ejemplo, hemos realizado una codificación TEI del manuscrito, no podemos desaprovechar ese trabajo. ${ }^{28}$ Así, el proceso de trabajo y producto «transcripción de manuscrito autó-

27 De hecho, cuando hablamos de transferencia del conocimiento y de obtener un eco en la sociedad a partir de proyectos digitales hemos de ser muy cautos. Hoy en día el mero uso del instrumento informático y de la publicación en web de contenidos científicos o culturales no constituye una noticia de por sí. Lo pudo ser en su momento, hoy ya no, si no es que el proyecto resulta realmente atractivo o llamativo o presenta alguna peculiar y particularísima novedad y capacidad informática. En su día fue noticia la digitalización en alta definición de El jardín de las delicias del Bosco. Seguramente hoy esa noticia no habría obtenido tanto eco. Es algo sobre lo que advertía hace ya una década Daniel Paul O’Donnell [2004]: «We are now long past the day in which electronic projects can be considered interesting simply because they are electronic». En realidad esta es una razón óptima para replantearse esfuerzos de trabajo dirigidos al objetivo único de la transferencia y divulgación: si esos objetivos no se cumplieran o, aun cumpliéndose, los beneficios reportados fueran muy fugaces, siempre quedará justificado el esfuerzo por su ulterior aprovechamiento propiamente científico.

28 Para los que todavía no saben qué es el etiquetaje o marcado TEI, qué son las etiquetas, aclararé: cada vez que introducimos un segmento de texto que responde a una determinada característica y que debe ser identificado como tal por la máquina, hemos de introducir una etiqueta. Todo segmento textual, en principio, debe ir marcado e identificado. Si habla el personaje Finea, deberemos marcarlo como personaje: <speaker $>$ Finea $<$ speaker $>$. Deberemos marcar asimismo su 
grafo» debería ser plena o parcialmente aprovechable dentro del proceso de trabajo y producto «edición crítica digital». Esto debería ser así para todas aquellas obras que decidamos editar digitalmente y que cuenten en su tradición tanto con manuscritos autógrafos como con impresos u otros testimonios, aunque los programas de trabajo podrían tener que variar en función de las circunstancias de transmisión.

El aprovechamiento del esfuerzo requiere una cuidadosa programación de las fases de trabajo. Se me ocurre, si hablamos en contexto TEI, que tal vez lo más prudente sería realizar una transcripción por capas o estratos. ${ }^{29}$ Vamos a ponernos en una situación hipotética pero nada extraña: una obra que se conserva en un manuscrito autógrafo con variantes de autor (pentimenti y correcciones diversos) y se transmitió también impresa en diferentes testimonios, incluidos impresos, y cuyo texto base para la edición será el autógrafo. Nuestro primer paso coincide con el principal objetivo: un texto bueno y lo más limpio posible de códigos, con una codificación básica, sencilla. Ahí habría que marcar elementos textuales básicos como el verso, el personaje, la acotación, la jornada, lista de personajes (y tal vez intérpretes) y otros elementos de este estilo. ${ }^{30}$ Una codificación más sencilla de elementos textuales básicos luego resultará plenamente aprovechable en otras fases de trabajo propias o, también muy importante, por otros proyectos de investigación ajenos, por ello deberá guardarse como oro en paño para introducir posteriormente ulteriores codificaciones y realizar diferentes tratamientos. Ese primer archivo básico se podría llamar y cumplir las funciones de documento maestro. Para

parlamento $(<\mathrm{sp}>\ldots</ \mathrm{sp}>)$, y dentro del parlamento, cada uno de los versos como tales al inicio y al fin y también con su número (por ejemplo: $<1$ n="1395">Id danzando cuando os vais. $</ l>$ ); también deberemos marcar las secciones de los versos truncados, etc. Estas etiquetas y otras similares constituirían un marcado básico y así obtendríamos un texto marcado con TEI. Podríamos marcar tantos aspectos de la obra como más tarde nos interesara estudiar, multiplicando las etiquetas. Por ejemplo, podemos marcar qué tipo de estrofa se usa. Si además queremos integrar toda la información sobre las variantes de autor o de los distintos testimonios en el propio texto, de manera que pudiéramos generar luego el aparato crítico, deberíamos marcar todas y cada una de las variantes, lo cual es ya más complejo, de hecho diría que puede ser bastante complejo (a veces, incluso, hay que idear «trampas» para engañar a la misma máquina para salvar sus limitaciones; aclaro, ahora para los especialistas: entiendo que las normas de anidamiento presentan limitaciones y que las anclas o anchors son las «trampas» con que se salva ese obstáculo).

29 Celebro ver que coincido en este planteamiento con Paul Spence: véase en este mismo número, p. 52. Consultados otros especialistas, en cambio, no lo han visto necesario.

30 Estamos hablando ahora de ediciones (born-digital), aunque no veo ningún inconveniente a la digitalización de buenas ediciones en papel para obtener este documento marcado con TEI básico. Si (y solo si) se puede garantizar que el texto permanece inalterado, en un flujo de trabajo adecuadamente diseñado, podría ser una buena solución para evitar que el filólogo perdiera más tiempo del necesario marcando segmentos textuales que no presentan dificultad. 
este archivo básico, para este documento maestro, se podría crear ya una hoja de estilo que permitiera una visualización en pantalla como un texto casi desnudo de aparato crítico o de notas. Para entendernos, su visualización sería similar a la que ofrecen actualmente las comedias en la página de Arizona (+), o las de Artelope (+). En la medida en que carecería de aparato crítico, este producto, de ninguna manera cumpliría los objetivos de PROLOPE de ofrecer ediciones críticas, aunque ciertamente el texto podría darse ya por bueno, perfecto, acabado. En cuanto a calidad y producto, sería ya nuestro texto crítico, el resultado del proceso científico que esa expresión connota.

En segundo lugar, sobre la base de este texto básico, introducir y codificar adecuadamente todas las variantes de autor. Hecho esto, ya tendríamos un producto, en cuanto al input de los datos se refiere, acabado y filológicamente relevante, y habría que elaborar un output, una hoja de estilo que confiriera a ese trabajo realizado ese carácter espectacular, didáctico y divulgativo que perseguíamos. Elaborado el input de las variantes de autor, se habría de estudiar su compatibilidad con las variantes del resto de la tradición y si sería posible su integración en un único aparato crítico. Si es compatible, seguiríamos adelante sobre la base del documento que incluía la codificación de esas variantes de autor. Si no, volveríamos al documento maestro con la codificación básica y en él se integrarían las variantes de la tradición: la lección final del manuscrito autógrafo y las del resto de testimonios. Ese fichero que decía se debe guardar como oro en paño, por otro lado, podría ser la base para elaboraciones futuras por parte de otros equipos y proyectos de investigación. El esquema de las fases de trabajo sería el siguiente:

Fase 1. Establecimiento del texto crítico y codificación básica TEI. Codificación mínima imprescindible para la conservación del fichero como material de trabajo y posible visualización austera del texto crítico desnudo. ${ }^{31}$

31 Para hacerse una idea de lo que considero esta visualización básica pueden verse las presentaciones de los textos de la biblioteca virtual ("plays») de la Association for Hispanic Classical Theater (www.comedias.org), o las del grupo Artelope en su Biblioteca digital (http://artelope.uv.es/); las ediciones digitales de este último grupo presentan un punto más de complejidad que bien podría asumir también Prolope en la que consideramos visualización básica: parece buena decisión de Artelope, por ejemplo, incluir la métrica en sus ediciones digitales y la capacidad de evidenciar esos segmentos básicos de texto de los que hablamos o interrogar sobre ellos; no implica un esfuerzo mayor de codificación (excepto la métrica) y sí una mayor capacidad de explotación del texto. En cualquier caso, recuérdese que por básica que sea la presentación, los textos ofrecidos por Prolope serán siempre críticos en la medida en que son resultado de un cotejo y proceso de establecimiento sobre los principios y métodos de la Crítica Textual. 
Fase 2. Sobre la base del archivo elaborado en la fase 1, codificación de las variantes de autor y elaboración de una hoja de estilo para una visualización divulgativa o espectacular.

Fase 3. Codificación de las variantes de todos los testimonios (estudio de la compatibilidad de las variantes de autor con las de la tradición completa) y elaboración de una hoja de estilo para una visualización científica de la edición crítica digital.

Las fases y tareas enumeradas se podrían representar así en el siguiente diagrama:

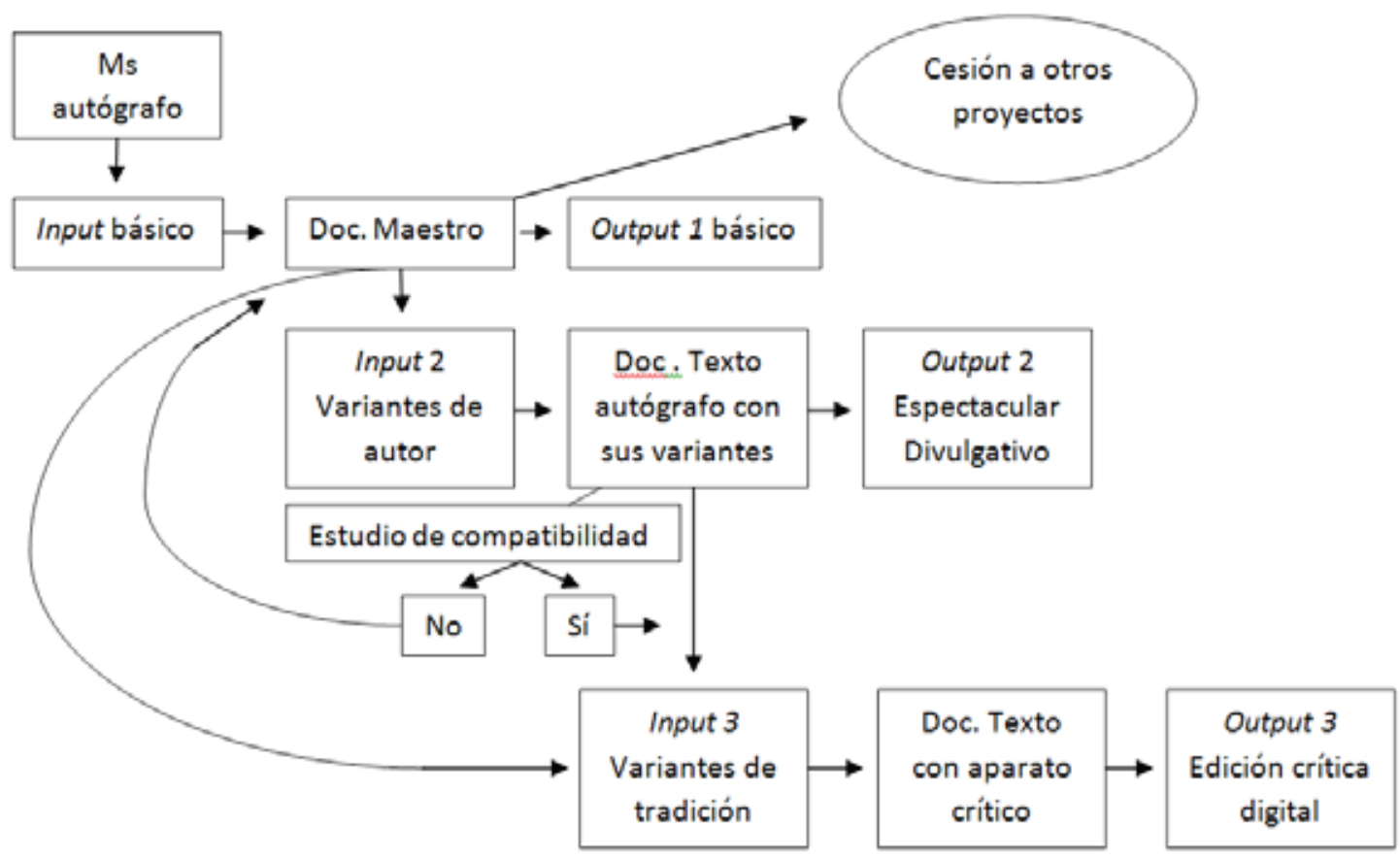

En cualquier caso, y como conclusión, ciertas fases de trabajo de la transcripción del manuscrito autógrafo deberían ser útiles tanto para un producto como para el otro. En los proyectos y productos de PROLOPE, tanto para la presentación del propio manuscrito como testimonio con toda su complejidad y atractivo para la presentación divulgativa del proceso creativo del poeta, como para su inserción posterior en edición crítica. A partir de cualquiera de los documentos generados se 
puede plantear la realización de capas de anotación más o menos compleja. Cabría plantearse en qué momento y sobre qué base conviene introducir la capa de notas. Así, si para cualquiera de los output se prevé la necesidad de anotación, se podría crear un documento maestro paralelo o un documento maestro 2 que contendría las notas aclaratorias y al que se acudiría como base para las siguientes fases.

Creo que es el momento de abordar otra cuestión también importante en los proyectos de Humanidades Digitales: las aspiraciones de Prolope en cuanto a la pervivencia de los materiales digitales que genere. Hace tiempo que venimos hablando de dos cuestiones, de investigar y de divulgar. Bien. Abordemos por tanto ahora qué queremos desde otras perspectivas, aunque igualmente prácticas. Seguiremos respondiendo a las preguntas iniciales. Hasta aquí hemos visto que queremos publicar y divulgar. Pero también almacenar y preservar. Voy a enunciar una serie de principios e intereses del grupo de investigación (de cualquier grupo de investigación) que, atendiendo a esos deseos e intereses, creo, deben tener unas consecuencias prácticas en sus decisiones respecto a cómo y con qué herramientas afrontar el proyecto de la edición digital.

\section{Perennidad e interoperabilidad de los Resultados}

En un proyecto de Humanidades Digitales, y en un proyecto de edición digital es necesario enumerar una serie de principios básicos y objetivos, aparte de aquellos de los que hasta ahora me venía ocupando. Los intereses y principios de los que ahora voy a tratar tienen que ver con las posibilidades y los riesgos reales que comporta el trabajo y la publicación electrónica y en red. La preocupación de los humanistas por la perennidad y universalidad o inteoperabilidad de los materiales elaborados no es en balde.

Ya tenemos experiencias, incluso en nuestro mundo, de la caducidad y obsolescencia de los productos. Muchos hemos visto cómo, después de pagar un alto precio para comprar una base de datos del Teatro Español del Siglo de Oro (TESO), caducaba en nuestras manos y dejaba de ser operativa, sin tener derecho siquiera a una actualización automática. Hemos visto cómo los discos que compramos de ADMYTE dejaron de funcionar y tenemos que pagar por acceder online. Hemos visto cómo una revista electrónica de calidad nacida en red, como Interletras, de 
la Universidad de Zaragoza, dejó de poder consultarse y desaparecieron todos sus artículos.

En el ámbito de las Humanidades Digitales, el proyecto más ambicioso y uno de los más grandes fiascos fue la Domesday Machine. Es historia, aunque haya adquirido rango de leyenda. El hecho no podía pasar desapercibido para filólogos como Daniel Paul O'Donnell [2004], medievalista interesado en recursos digitales cuyo relato seguimos. El Domesday Project, dotado de un presupuesto de dos millones y medio de libras, pretendía difundir y celebrar el noveno centenario del Libro de Domesday (una especie de censo de Inglaterra elaborado en el año 1086) en su contexto histórico gracias al uso de la realidad virtual y de sofisticadas máquinas y software especialmente diseñados para ello (incluso miniordenadores y reproductores de discos láser $a d$ hoc). Al final, todo el material quedó obsoleto y resultó prácticamente ilegible en el transcurso de quince años... a diferencia del propio Libro de Domesday, códice por el que habían pasado novecientos años, en perfectas condiciones de consulta en la biblioteca del Archivo de Kew. Al presupuesto inicial, luego hubo que añadir más proyectos y gastos para poder recuperarlo después de que se publicara la noticia en The Observer y estallara el escándalo en 2003. En ese año un experto informático declaró, sarcástico, que «tenemos suerte de que Shakespeare no escribiera en un ordenador personal». Ni el peor papel ácido de publicación de novelas de terror o prensa amarilla a inicios del siglo xx ha sufrido ese deterioro, llegó a decirse. Las posibilidades prácticas y los costes económicos de la preservación de los materiales digitales, con todo lo que ello comporta en términos de hardware y software, está todavía por descubrir, según O’Donell..$^{32}$

Hay otras preguntas que debemos plantearnos, puramente prácticas, muy básicas. ¿Por qué hemos dejado de poder consultar Interletras? Sencillamente, porque el proyecto decae, se deshacen los grupos, o incluso, porque se mueren las personas que lo promovieron (así ocurrió concretamente con Interletras, tras el fallecimiento de su promotor, Gonzalo Corona Marzol). Tal como venimos publicando hasta ahora, en soporte papel, scripta manent... pero... ¿seguirá permaneciendo lo escrito con nuestras publicaciones en web? Las páginas web conllevan un coste y un mantenimiento... Mientras no existan unas estructuras, un sistema y un protocolo de archivo

32 El fiasco se puede justificar, en parte, porque estábamos en los inicios de las Humanidades Digitales. Con todo, la preservación y recuperación de materiales digitales sigue siendo un problema y se ha generado ya naturalmente la disciplina llamada "Arqueología Digital», cuyo cometido es precisamente la recuperación de documentos y contenidos digitales. 
universal y fiable de los productos electrónicos, es tema que nos tiene que preocupar. ¿Prolope seguirá existiendo in aeterno?, ¿Artelope? Es posible, pero no seguro; más bien difícil. ¿Qué puede pasar con nuestros trabajos y nuestras páginas web si nadie presupuesta su mantenimiento?; incluso desde un punto de vista puramente técnico, ¿la programación y los lenguajes en ellas utilizados serán perennes? ¿Qué pasa cuando el producto de nuestra investigación es sobre base electrónica? Un documentalista o bibliotecario sabe qué debe hacer con un libro, pero ¿sabe a estas alturas, en 2014, qué debe hacer con una base de datos publicada en red? ¿Entra en sus competencias? Debemos nosotros ocuparnos de llevar nuestros materiales a un repositorio digital institucional. Tal vez ahí se garantice su supervivencia en el futuro. Mientras que el mecanismo de archivo de una publicación en papel, sea revista o libro, está garantizado, nos preguntamos si ocurre lo mismo con el producto informático (entendiendo como tal no solo los datos, sino también sus funcionalidades). ${ }^{33}$

En estas circunstancias, los humanistas, los filólogos, ¿podemos despreocuparnos de la perennidad de nuestros logros científicos? Creo que las lecciones aprendidas de proyectos como este, como Domesday, Interletras o TESO no deben caer en saco roto. Suzanne Keene [2002], conservadora del British Museum y profesora del University College of London, autora de diversas publicaciones sobre la preservación digital, mantiene:

33 Existen especialistas y organismos, dentro de los sistemas bibliotecarios, dedicados a la preservación digital. En Cataluña, por ejemplo, la Biblioteca de Catalunya creó en 2005 PADICAT (Patrimonio Digital de Cataluña) desde el ámbito institucional. En el País Vasco, en 2007, se creó Ondarenet, con el mismo objetivo. La Biblioteca Nacional de España encarga desde 2009 capturas anuales del dominio «.es» a Internet Archive. En todo el mundo existen unos 35 proyectos en funcionamiento de este tipo (la mayoría asociados al International Internet Preservation Consortium, IIPC), siendo el más conocido el estadounidense, el mencionado Internet Archive —agradezco estos datos a Ciro Llueca Fonollosa (PADICAT)—. Tenemos ciertas garantías de supervivencia en este sentido, en la medida de que estos problemas afectan a cualquier disciplina, iniciativa o institución pública o privada que utilice la herramienta informática, hoy en día casi todas. Pero todo aquello que se desee que sobreviva tendrá que tener una adecuada voluntad, atención, gestión y presupuesto económico para la supervivencia, y por ahora no hay que darlo por descontado, como podemos hacer con nuestros productos en papel. De hecho, el modo de actuar de PADICAT no garantiza la supervivencia de todo material digital. Y es un servicio centralizado: por ahora no existen especialistas ni programas de preservación digital en todas las bibliotecas o instituciones ni pueden absorber la masa de material digital generada. Me atrevo a afirmarlo tras consultas y entrevistas con bibliotecarios de mi propio sistema universitario y del PADICAT. Véase también lo dicho por Paul Spence en este mismo número (pp. 63 y 66), a lo que aquí añade Spence un ulterior problema: el de la cita científica y la estabilidad del producto (las diferentes versiones del producto científico en su evolución y crecimiento obligan a imaginar soluciones nuevas de cita para una realidad más compleja: lo planteaban solo en el mundo en papel las ediciones revisadas, reimpresiones o reediciones y tampoco en ese ámbito le hemos prestado nunca suficiente atención). 
The first principle of digital preservation is: Decide at the time when it is created how long the material is to last. This will affect the standards used, the software technology (for example, a more expensive but standard database management system might be necessary), the upgrade path, the staff and technological resources necessary to manage the digital asset for the future.

Afortunadamente, en nuestro grupo de investigación, y hasta donde se me alcanza, en el resto de grupos que nos dedicamos a teatro del Siglo de Oro, estos planteamientos son oportunos en este momento. Estamos, unos, dando los primeros pasos; otros, planteándonos iniciar el camino digital; y, por último, otros que ni sueñan con ello y prefieren mantenerse en el papel. Hay consejos planteados por Keene que escapan a nuestras competencias y posibilidades. No podemos planificar el presupuesto y personal para el mantenimiento de nuestros proyectos y resultados de investigación en el futuro. Ahí ya tenemos que delegar y confiar en los bibliotecarios y documentalistas. Por el momento parece prudente encargarnos nosotros mismos de hacer llegar nuestros productos a repositorios digitales. Pero hay otras decisiones que es ahora cuando las tenemos que tomar y sí dependen de nosotros. Nuestra aspiración, desde luego, por ambiciosa que suene, no puede ser otra que la perennidad de nuestros productos y resultados científicos.

Según Keene [2002], una conservación de materiales digitales a largo plazo requiere "careful attention to standards, metadata, their technological basis, to maintaining off-site copies, and to strategic planning for their future technological path». En la misma línea de Keene, en su artículo dedicado al fiasco del Libro de Domesday, Daniel Paul O’Donell [2004] enunciaba tres principios para la supervivencia de los materiales digitales:

1. No escribir para software o hardware específicos ni utilizar lenguajes no-standard.

2. Mantener la diferenciación entre contenidos (los datos) y presentación (la visualización).

3. Evitar innovaciones técnicas innecesarias.

Las lecciones aprendidas a través de la experiencia y los consejos de los especialistas parecen ser, pues, bastante claros. Sigamos. 
7. Publicación, universalidad y Compatibilidad de los Sistemas.

COMUNICACIÓN, INTERCAMBIO Y COOPERACIÓN EN LA ELABORACIÓN DE LOS MATERIALES

Los diferentes objetivos y principios tal vez puedan lograrse y respetarse a través de la interrelación de todos ellos. Así, si una edición de Prolope se basa en un sistema de transcripción propio, un software propio y sólo se publica y da a conocer, sin permitir que se pueda «exportar», estamos condenándola al confinamiento, a un eco limitado y a su posible desaparición final. Si, en cambio, entrando en la filosofía de la web, nos preocupamos de elegir un sistema de transcripción y marcado standard, un programa o programario gratuito y compartido, y si se permite descargar el texto a otros investigadores trabajando en filosofía web, de modo colaborativo, tal vez, digo, así, estemos garantizando mejor su supervivencia.

Efectivamente, si nosotros realizamos nuestra edición con un lenguaje de codificación estandarizado, si permitimos que, sobre la base de nuestro texto, otros trabajen, es decir, si les ofrecemos nuestro texto, lo estamos compartiendo y poniendo en circulación. Sin embargo, acecha aquí un peligro de nuevo que debemos conjurar. En la manipulación ajena, el texto como tal debería permanecer inmutable o bien ser solo modificado con nuestro permiso. Si hablamos de codificación, pueden quitarse o añadirse etiquetas, por ejemplo, pero no pueden tocarse las cadenas de caracteres que componen el mero texto: las palabras y la puntuación. ¿Se puede conjurar este peligro? Me temo que no. Por eso, al final, la copia y la réplica no son ninguna garantía para la supervivencia de nuestra labor y objetivo: precisamente unos buenos textos. Tal vez la multiplicación al menos inicialmente controlada de la presencia de copias de nuestros textos en internet, a través de pactos y la firma de convenios con otros proyectos de investigación e instituciones, sí podría ser una buena opción. Aunque, desde luego, si entramos en el juego de la red y la web 2.0, al final hay un riesgo importante de que escape a nuestro control. En algún momento podríamos encontrarnos en una situación similar a la que se encontró Lope: nuestros textos, que tanto trabajo nos ha costado editar, circulando, deturpados por manos ajenas, pero todavía a nuestro nombre. Es obvio que en un proyecto de investigación que tiene por norma y norte el logro de textos limpios no es una situación deseable y debemos intentar evitarlo.

Así pues, al final, es el propio grupo el que se debe preocupar de crear unos productos perennes, que circulen y que a la vez circulen con seguridad y manteniendo la calidad textual que ha motivado el esfuerzo. Tal vez la única salida segura sería la 
publicación simultánea en red y en papel. O la elaboración, cuando menos, de documentos pdf en formato libro. Aunque así se perdería, claro, parte de las ventajas de trabajar en formato electrónico y en red, por lo menos tendríamos la garantía de la supervivencia del texto, del texto crítico. Desde luego, la preservación del texto tal como ha sido establecido es una prioridad para ProLope. En este sentido podría ser bueno ofrecer un doble producto de publicación, en red y en papel, así como interactivo y dinámico uno, el otro estático y estable (sea papel o pdf), a partir de un único esfuerzo de trabajo.

\section{Sueños y realidades digitales. Software Y Plataformas de Edición}

Hasta aquí he procurado dar unas ideas de qué es lo que queremos, qué productos queremos conseguir (transcripciones de manuscritos, ediciones críticas), y algunos objetivos y condiciones que deben cumplir (divulgación, perennidad, interoperabilidad). Ahora quiero abordar otra cuestión. ¿Cómo querríamos poder hacerlas? ¿Qué software utilizar? ¿Qué condiciones de trabajo pretendemos? Y más allá de esto, ¿qué atisbamos que nos podría ofrecer la herramienta informática más allá de lo que ya nos ofrece? Y todavía una pregunta más: ¿se puede hacer una edición crítica digital de una obra sin un largo y profundo entrenamiento? ¿Lo permite algún programa, algún recurso informático?

Esta última pregunta responde a una razón, una realidad: en nuestra estructura de trabajo, requerimos la colaboración simultánea de numerosos estudiosos, pongamos unos sesenta, cuando no más (muchas comedias se editan en colaboración). Normalmente tenemos unas cinco Partes de comedias en diferente estado de ejecución, pero todas en marcha simultáneamente. Sería muy difícil poder entrenar a todos nuestros colaboradores en cualquier software o lenguaje de codificación.

\section{Organización del trabajo en Prolope}

\section{PROLOPE: 112 comedias editadas aprox. 168 por editar}

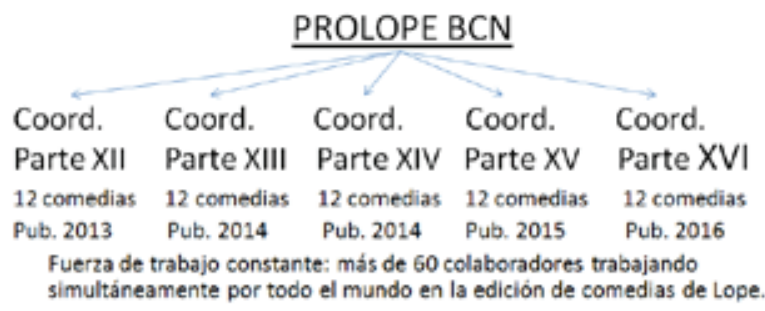


Es cierto que, por ejemplo, para lo que es una codificación básica del texto en TEI se podrían crear interfaces o pantallas de trabajo más o menos cómodas y automatizaciones relativas de los procesos como se ha hecho en otros proyectos, como Artelope, según la interesante explicación de C. Muñoz [2013], o con anterioridad, el proyecto TESORO (J. T. Nogales 2003). ${ }^{34}$ Sin embargo, la elaboración de un aparato crítico resulta ya bastante más compleja y esa solución no parece, en nuestro caso, por el momento, viable para el proyecto principal de las comedias publicadas en Partes. Y aunque el organigrama que he expuesto se refiere a las comedias publicadas en Partes, nuestra estructura de trabajo para acometer la edición de los diferentes corpora antedichos vendría a ser más o menos similar, con previsible dependencia de colaboradores externos esparcidos por diferentes lugares del mundo.

Por enfrentarnos a otro problema práctico, tampoco podríamos pagar licencias por instalación en el ordenador de cada uno de ellos si quisiéramos trabajar con un programa como Classical Text Editor ni, en el caso de instalarlo en un servidor común y pagar la cara licencia correspondiente, algunos de ellos podrían o querrían recibir el entrenamiento necesario para usar dicho programa o para codificar con TEI. Desde luego, si hubiera un programa libre y sencillo que se adaptara a nuestras necesidades, esa sería nuestra elección. TEI, en su actual estadio y formulación, y por sus características de lenguaje de marcado, pero no de software o interfaz amigable, es en principio inaplicable en un proyecto que implica tantos colaboradores y tan dispares en su potencial conocimiento, afección e interés por los recursos informáticos. Hay un argumento simplísimo: no podemos prescindir de la colaboración de editores que pueden negarse a colaborar con nosotros en el caso de que les impongamos la tarea de aprender a editar con TEI, pero yo diría, ni siquiera con Classical Text Editor, que también requiere un entrenamiento y conocimiento

34 El artículo de J. Tomás Nogales [2003] es interesantísimo: ofrece una descripción con pormenores técnicos de todo el proceso, desde la digitalización hasta la publicación en página web, relatando algunos problemas encontrados, la creación del DTD, el TEI header, la hoja de estilo, características técnicas del servidor, etc. Por desgracia, temo que la información resulte ya obsoleta por el año de publicación del artículo y realización del proyecto, que quedó paralizado. El proyecto, que se planteaba la digitalización de doscientas obras del teatro clásico, quedó al final en cinco, pero su experiencia es de por sí, como el título del proyecto, un verdadero tesoro. Se trató, eso sí, de digitalización de ediciones preexistentes publicadas en papel, no ediciones born-digital (de hecho los integrantes del proyecto eran documentalistas). Y aunque algunos textos pueden ser críticos, no se puede decir que sean tales las ediciones, dado que los textos van desnudos de ningún tipo de aparato (ni notas aclaratorias, ni aparato de variantes). Se puede encontrar también una detalladísima descripción de todo el proceso en la página del proyecto TESORO. http://www.bib.uc3m.es/ nogales/ xml/tesoro/index.html\#enti 
profundo del programa. ${ }^{35}$ La conclusión puede ser solo una: desde nuestro grupo de investigación, por ahora, podemos acometer ediciones digitales de manera experimental, puntual y limitada a los corpora y casos que he mencionando al inicio de estas páginas.

En este punto, me atrevo a plantear una pregunta: ¿se han desarrollado los recursos informáticos para la edición crítica digital lo necesario como para ser autosuficientes y poder satisfacer nuestras necesidades? Creo que no nos queda más remedio que admitir que la respuesta realista por ahora es no. Cuando el filólogo escribe un aparato crítico está redactándolo en un lenguaje formalizado. ¿No debería de ser capaz de entenderlo e interpretarlo la máquina? En este sentido, cabe hacer una reclamación acorde a las más clásicas Humanidades Digitales, y que va en el sentido de "humanizar» a la máquina y hacerla capaz de interactuar con el hombre de un modo más sencillo, intuitivo y espontáneo. Son problemas clásicos del desarrollo de la informática que vienen planteando las necesidades de la amigabilidad de la máquina y sus lenguajes y del diseño centrado en el usuario desde Vannevar Bush o Joseph Carl R. Licklider (véase Numerico, Fiormonte y Tomasi 2010:25-29 y 37-40). No cabe duda: hemos dado pasos de gigantes. TEI, TUSTEP, Juxta, Classical Text Editor, son pasos en la dirección correcta (véase el artículo de F. Tomasi en este número), pero... el precio de unos, las limitaciones de otros, la sofisticación y dificultad de uso del primero se nos antojan obstáculos muy importantes para proyectos de edición de las dimensiones de los que estamos hablando. Es una pena, pero es así. Y paralelamente, hay que admitirlo, ¿qué esfuerzos estamos dispuestos a hacer los filólogos en nuestra formación digital? Muchos esfuerzos algunos: los humanistas digitales; pocos, algún esfuerzo; la mayoría, ninguno. Es una pena, pero es así. Pero precisamente por eso hay que aprovechar cualquier brecha en esta situación, cualquier intento de aproximación, en un espíritu de colaboración y superación de obstáculos.

Quiero justificar lo que digo. Entramos en un debate fundamental. Me ocupo ahora específicamente de TEI. Dice una de las máximas de los miembros del

35 Según Pusceddu [2003:4]: «Spesso molto complessi, i software per l'ecdotica elettronica richiedono studio e corsi specifici per l'apprendimento dei comandi (TUSTEP) o competenze informatiche di base notevli (EDMAC, CET)». Un curso de una semana, por poner un ejemplo, permite solo empezar a familiarizarse con los lenguajes, programas o programarios que estamos comentando. Por supuesto estoy hablando de nuestra situación actual: sin duda en unos años las competencias informáticas de los graduados universitarios serán superiores y la situación cambiará. 
consorcio TEI que el trabajo de codificación es un trabajo de especialista. Espero que sea solo una máxima, y no un dogma, porque entonces tendría la fuerte tentación de declararme, desde ya, permítaseme la broma, "ateísta». Eso va en contra de la voluntad de entendimiento y espíritu de colaboración. Espero comprensión si digo que el especialista, el filólogo, debe poder recoger las variantes de los distintos testimonios, pero ¿debe ir marcando pacientemente como verso cada verso? ¿Cada número de verso? ¿Como parlamento, cada parlamento? ¿Como personaje, cada personaje? ${ }^{36}$ Identificar y marcar un verso como tal, o un verso truncado, o una acotación, no requiere de los conocimientos de un especialista. Es, más que nada, un trabajo mecánico de pura paciencia y sin mérito científico alguno, digámoslo claro. Y de hecho, es un error sostener que es tarea de especialista. Tal vez cómo identificar y señalar una variante especialmente compleja (por inusual, ambigua o interpretable), sí lo sea. Y por supuesto lo es el establecimiento del texto a partir del cotejo... claro que sí, pero eso es el trabajo filológico que hay que distinguir de la labor de marcado y digitalización. Idear un sistema de visualización de las variantes, el output de la edición, también es un trabajo científico y filológico, pero lo es, seguramente, en colaboración con el humanista digital o con el ingeniero informático con quienes deberán encontrarse las soluciones técnicas o incluso las mejoras respecto a las ideas del filólogo.

La diferencia fundamental con un procesador de textos actual, con una pantalla más intuitiva y clara, es que con este escribimos prácticamente de manera espontánea y natural aquello que queremos que se vea, el aspecto final del texto, lo que vamos a obtener: lo que se conoce en términos informáticos como «wysiwyg» ("what you see is what you get»: 'lo que ves es lo que tienes', frase acuñada por el ingeniero Larry Sinclair a principios de los ochenta para referirse a una interfaz amigable, sumamente intuitiva ya que su visualización se acerca mucho al aspecto final que tendrá el documento impreso, como por ejemplo la de Microsoft Word). Sin embargo, si estamos marcando con códigos TEI tendremos un escrito lleno de porciones de texto y de etiquetas que identifican el contenido de dichas porciones. Dependiendo de nuestros objetivos y del volumen de etiquetaje el texto puede quedar prácticamente escondido. En el ejemplo que adjunto he marcado las etiquetas en rojo $(+)$.

36 Unas notas más arriba, en las 16 y 28, he descrito sumariamente el proceso de marcado y remitido a referencias donde se explica con algo de detalle el mismo. 
Aquí es donde pido un ulterior auxilio de los informáticos. No me basta que hayan creado un lenguaje de marcación. Me hace falta que lo automaticen, que lo hagan más amigable, que hagan más fácil, automático, cómodo y humano su uso. ${ }^{37}$ Yo soy un hombre y no quiero escribir en lenguaje máquina (ya sé que TEI no es «lenguaje máquina»... pero creo que se me entiende; a mí me lo parece). En este sentido, a pesar de ser TEI una iniciativa que por supuesto va en el camino de las Humanidades Digitales se ha quedado a medio camino en la humanización de la máquina y pretende la mecanización del humanista, que si quiere usar TEI sin otros auxilios o desarrollos deberá ir marcando como máquina verso por verso. No creo que debamos ceder terreno... La máquina no es un enemigo, está a nuestro servicio y debemos aproximarla todo lo posible a nuestras necesidades. Debemos seguir insistiendo en la humanización de la máquina o del lenguaje de la máquina, tal como en su momento hicieron Bush o Licklider. Creo que ahí, en el terreno de la Filología Digital, o incluso para ser más exactos, de la Informática Filológica, queda camino por recorrer, y solo lo podemos recorrer codo con codo con los ingenieros (o los humanistas digitales). ${ }^{38}$

Creo que el editor crítico de nuestro teatro debería disponer de una interfaz de uso común, no asociada a proyectos concretos, donde se le ofrecieran distintos botones con nuestros segmentos básicos de texto. Menú texto: verso, verso partido, fragmento en prosa. Menú métrica: las distintas estrofas y metros (el programa solo debería cumplir con el sangrado algo mayor de cada inicio de estrofa). Menú escenografía: personaje, acotación, aparte. Se me ocurre que la propuesta de Carlos Muñoz [2013] para Artelope presenta muchos puntos aprovechables y va en el buen camino. Tal vez estaría pensando en un software, si se pudiera, todavía más humanizado y amigable. Pero sea como sea, a ello deberíamos añadir ahora un Menú

37 Véase lo dicho por Paul Spence en este mismo número sobre la interfaz amigable: p. 54 y n. 20.

38 Dentro de las diferentes y posibles definiciones del «humanista digital», la de Francesca Tomasi es más restrictiva o exigente y es a la que me quiero referir aquí; según esta filóloga italiana, el «humanista digital» tiene un conocimiento igualmente profundo en Humanidades y en Informática. Otras visiones menos estrictas defienden que el humanista digital es aquel que propone y trabaja en proyectos digitales codo con codo con ingenieros, pero sin un profundo conocimiento informático más allá del que resulte necesario para poder comunicarse adecuadamente con ellos (postura esta de la que es más partidario Paul Spence). Aclaro que ambos son filólogos. Véase también lo dicho por Paul Spence (pp. 61-62) en este mismo número respecto a los proyectos de Humanidades Digitales como trabajo en colaboración, con pérdida de la relativa independencia de que gozaba el humanista hasta la actualidad. 
Aparato crítico: testimonios, tipos de variante: de autor, de tradición, redaccional, lingüística, errata, omisión, adición, transposición, etc. Si lográramos definir y automatizar un grupo básico de variantes habríamos avanzado algo y creo que sería positivo. Con todo, creo que sería intentar vender humo decir que podríamos conseguir un editor de TEI equivalente a un procesador de textos de uso común que automatizara la codificación de todas las posibles y diversas variantes que se presentan en la historia de la transmisión textual del teatro de Lope de Vega. Al final, siempre va a ser necesario un grado de conocimiento profundo del lenguaje TEI para solucionar ciertos problemas. Lo que sí podríamos lograr es evitar todos los aspectos más reiterativos y mecánicos de marcado y agilizarlo enormemente. Es algo factible, pero se deja en manos de cada proyecto, de modo que siempre, incluso para esta parte básica, se depende de un informático. Si lográramos penetrar por ahí, seguramente se produciría un aprendizaje más inconsciente, ${ }^{39}$ más intuitivo del lenguaje de marcado y podríamos afrontar mejor y concentrarnos en lo verdaderamente problemático desde un punto de vista textual.

Baste lo dicho hasta aquí respecto a la fase de fijación del texto o transcripción de nuestro texto base. Pero me gustaría decir algo más todavía, unas meras notas sueltas, antes de las conclusiones, sobre las posibilidades de aplicación de la informática a otras fases de la Crítica Textual. Hace ya muchos años que se viene hablando de las posibilidades que ofrecería el desarrollo la Informática Filológica. Sin embargo, todavía hoy, en 2014, la mayoría seguimos trabajando de un modo muy tradicional... artesanal. Incluso los que estamos interesados en los recursos informáticos para la Filología, me atrevería a decir, nos sentimos algo desorientados, desinformados, y aunque estemos deseándolo, tenemos miedo a dar los primeros pasos. Debería existir tal programa, tal otro, pero... o no existe, o no se ha extendido su uso y no lo sabemos. Pusceddu y J. M. Lucía Megías informaron sobre ciertos programas y experimentos editoriales, pero no son de fácil acceso. ${ }^{40}$ Hay que prestar atención al artículo de

39 Me atrevo a comparar la situación con la que se producía por parte del usuario del programa WordPerfect hasta su versión 7, en sistema operativo DOS. El usuario que lo quisiera podía activar la opción "mostrar códigos» y entendía perfectamente, gracias a una sección de pantalla inferior, dónde había marcado que debía iniciar el uso de una cursiva, una negrita o cualquier propiedad del texto: así aprendía a entender las necesidades de la máquina y podía hacer las correcciones necesarias. En ámbito Windows se trabaja más a ciegas, en este sentido. Remito de nuevo, para este tema, a lo dicho por Paul Spence en estas mismas páginas (p. 54) y su cita de Vanhoutte en torno al rechazo de algunos humanistas al trabajo con etiquetas o marcas (n. 20).

40 Tal vez uno de los programas que se pone al alcance del editor, sumamente intuitivo y freeware, es Juxta, aunque sus capacidades son limitadas. 
Francesca Tomasi en este número. Nos queda mucho por conocer, mucho por utilizar adecuadamente, y algo también queda por desarrollar.

Muy rápidamente: el metacatálogo de la Universidad de Karlsruhe es una excelente herramienta para la búsqueda de bibliografía primaria (fontes criticae), pero cabría mejorarla: muchas veces las consultas no se completan en muchos de los catálogos enlazados. Viene hablándose hace años de la colación y filiación automáticas, pero no se han extendido. Para mí está claro que la informática nos podría auxiliar mucho, con análisis automatizado de imágenes, como mínimo en el cotejo de ejemplares de una misma edición. ${ }^{41}$ Los programas que nos podrían auxiliar en el análisis de variantes y filiación de testimonios se antojan bastante obvios. Se nos da noticia de la existencia de algunos; ${ }^{42}$ otros los vemos en funcionamiento: por ejemplo, el histograma que ofrece Juxta para el análisis de concentración de variantes. Un buen gestor de las variantes capaz de reagruparlas por testimonios o un analizador gráfico que reprodujera las variantes en stemma son aplicaciones sencillísimas que todos deberíamos poder usar (+). En fin, en cuanto a la anotación, Prolope viene trabajando hace un tiempo por loable iniciativa de Guillermo Serés en una base de datos en que se reúnen y se pondrán a disposición de la comunidad las notas elaboradas por sus editores en sus 124 ediciones. ¿Sería muy dificultoso que el editor que esté introduciendo el texto reciba un aviso cuando transcriba una palabra que ya ha sido anotada y pueda ver una sugerencia de anotación? Varias de las utilidades que imagino y propongo requerirían de una interconexión entre las distintas utilidades y bases de datos textuales. Estaríamos hablando más que de una página, o un mero editor de textos, de un taller de edición con diferentes utilidades y almacenes de datos: imágenes, textos, bibliografía primaria, secundaria, obras lexicográficas, paremiológicas, enlaces... No es nada novedoso. Sin embargo,

41 Respecto a la ignorancia del programario que nos podría auxiliar: realicé esta consulta en público, en el congreso valenciano antes mencionado, entre prestigiosos colegas con proyectos digitales en marcha e informáticos, y nadie supo darme una respuesta. Consultando con A. Bía Platas en otra ocasión, daba por supuesto que existía esa posibilidad, pero no conocía programa específico. Consultada Elena Pierazzo en Berna, durante el workshop sobre TEI de septiembre de 2012 ya mencionado, me respondió que en el King's College lo habían intentado y no había funcionado, aunque no me señaló bibliografía de balance al respecto.

42 Respecto al software e incluso al debate en torno a la colación y la filiación automáticas, remito a Morrás [2003:225-226 y 237, n. 3], aunque también hay que prestar atención a las más recientes aportaciones de Pusceddu [2003:2 y 5-7; véanse también las actualizaciones en la página de Digital variants] y Tomasi, en este mismo volumen. 
tampoco han acabado de ponerse en marcha. ${ }^{43}$ No parece deseable que este «taller del editor» fuera la página de lectura de los textos para el público general. En la página de lectura para el público general los textos estarían ya convenientemente fijados, serían textos críticos, y los materiales de acompañamiento para su comprensión convenientemente seleccionados. Tal vez se podría concebir, para el curioso, una "visita guiada» por el taller de edición, pero la hiperedición no puede ser una escapatoria para el editor, que, como ya hemos dicho, debe ser responsable de sus decisiones editoriales y ofrecer al lector un texto convenientemente editado, fijo, perfecto y un material de acompañamiento cerrado y limitado que lo haga abarcable y, en esa medida, útil.

En fin, creo que más que programas, que tal vez siguen usándose más como procesadores de textos, deberíamos ofrecerle al editor en un lugar, y al lector en otro, unas herramientas de acompañamiento de la edición y la lectura. ${ }^{44}$ Desde luego, deberían de estar los testimonios para la constitución del texto, pero también podría haber otra bibliografía primaria o secundaria. Obras básicas de lexicografía, manuales de métrica, de ortología, iconografía, polianteas, etc. Esto servirá al editor del teatro del Siglo de Oro. Es obvio que el taller se construirá según las necesidades de los textos a anotar...

Bueno, quedan aquí unas cuantas ideas. Y muchas preguntas... Seguramente las primeras podrán encontrar desarrollo en otros artículos de este mismo volumen y las segundas, algunas respuestas.

\section{ReCAPitulación y CONCLUSiONES:}

LA URGENCIA DE LA EDICIÓN DIGITAL

Como ya se ha indicado, la hiperedición abre nuevas posibilidades a la hora de enfrentar la edición crítica de una obra, es decir, la comprensión global de su génesis

43 La iniciativa de la Universidad de Tuebingen, TUSTEP, por desgracia cuenta con un inconveniente, que podría parecer banal, pero que hemos de reconocer es un verdadero obstáculo para su expansión: todos sus manuales están en alemán sin traducción a ninguna otra lengua. Debe mencionarse aquí, en esta línea, el portal del Teatro de los siglos de Oro, dirigido por R. Serrano Deza y A. Hermenegildo, con distintas utilidades de análisis textual de interés. Véase también Serrano Deza [2001].

44 También ha hablado J. M. Lucía Megías [2007/2009:39] de espacios de conocimiento, en los que se puede producir la interacción entre el lector y el editor y foros de debate. Véase también M. Morrás [2003:29] y la propuesta que presentará Marco Presotto para La dama boba. 
y transmisión. El editor no se encuentra, como sucede en la actualidad al difundir su trabajo en libros impresos, con ciertas limitaciones tanto tipográficas como editoriales; todo lo contrario: la hiperedición no solo permite incorporar abundantes materiales sino también de naturaleza muy diversa: desde las reproducciones facsímiles al sonido.

Hace unos años, la profesora Blanca Periñán al hacer un balance de los estudios hispánicos en las últimas décadas terminaba con una (triste y matizada) conclusión: la crítica literaria en España podía caracterizarse como un «vuoto». A una misma conclusión llegamos al analizar la presencia de la literatura española en la Red, al margen de algunos proyectos muy meritorios y con grandes pretensiones, que son los que hemos comentado y comentaremos en las siguientes páginas, sin intención (que resultaría imposible en el caso de Internet) de ser exhaustivo. Frente a los proyectos anteriormente analizados, y lo que sucede en otros países como Francia, Gran Bretaña o Estados Unidos, no contamos actualmente en el ámbito del español con proyectos similares que tiendan hacia la acumulación $-\mathrm{y}$ sistematización- de toda nuestra literatura. Existen, eso sí, proyectos temáticos y parciales, con unas características peculiares y con unas posibilidades de un uso científico en ocasiones muy criticables (Lucía Megías 2000:415-416).

Escalofriante, me atrevería a decir, pero cierto: la referencia que doy entre paréntesis es correcta. J. M. Lucía escribía estas palabras en el año 2000. Han pasado trece años y yo diría que, en sustancia, la situación sigue siendo la misma, unos pocos proyectos muy meritorios, pero el panorama de la edición crítica digital en España es desolador. Seguimos en un círculo vicioso que retrataba también María Morrás [2003:233 y 235] y del que se lamentaban algunos filólogos, según ella refería entonces... desde 1993 (y ya hemos alcanzado el ventenio):

En la ya extensa bibliografía sobre el tema, abundan las descripciones de proyectos en marcha, los trabajos que exponen in futuro las maravillas de la informática y sus trascendentales consecuencias para el progreso y orientación de la crítica textual. Pasan los años, sin embargo, y una parte considerable queda en pura quimera. Los proyectos quedan desfasados antes de que concluyan, los programas que tanto costó aprender son reemplazados antes de que se resuelvan los problemas que se han detectado en su empleo, y en los trabajos teóricos se formulan metas cada vez más ambiciosas y más lejanas, sin que parezca se llegue nunca a ellas. Este desfase entre el deseo - lo que la informática promete- y la realidad ha generado un profundo escepticismo entre los editores «artesanales», al que se suma la frustración de los 
que mantienen una actitud más abierta pero están desorientados ante la falta de certezas sobre lo que existe y podrá existir efectivamente [entre estos me atrevería a contarme...] No puede negarse que la larga espera no solo causa escepticismo y desconcierto (Lancashire 1993:325; Robinson 1993:285), sino que impide comprobar los límites y posibilidades del formato del hipertexto para una edición (Faulhaber 1991). Como la crítica textual se basa en el método del ensayo y el error, hasta que los editores no dispongan de un texto crítico y de todos los materiales suplementarios en las pantallas de su ordenador tal como describen los proyectos, será difícil decidir cuál es la metodología más pertinente.

Así seguimos. En lo que he venido diciendo en estas páginas, he planteado una serie de posibilidades, de sueños, de proyectos. Creo que llega el momento, si es que no ha pasado ya, de ponerse manos a la obra. En esta ocasión no va a quedar en pura quimera. En el grupo Prolope ya hemos dado un primer paso. Marco Presotto, cuando escribo estas líneas, tiene ya prácticamente acabada una transcripción filológica con TEI del manuscrito autógrafo de La dama boba en que se recogen las variantes del proceso de composición. Vamos a afrontar también ediciones críticas digitales.

Recapitulando, podemos concluir:

1. La edición crítica digital puede ofrecer soluciones mejores científicamente que la edición analógica y tradicional.

2. La publicación en web implica mayor difusión para nuestro trabajo.

3. El trabajo en formato digital facilita la colaboración con otros grupos de investigación.

Ergo...

4. Prolope quiere acometer la edición crítica digital.

5. TEI, standard de facto (lo que facilita su interoperabilidad y perennidad) parece una herramienta adecuada para empezar a experimentar, no obstante su nivel de complejidad. ${ }^{45}$

45 Según J. M. Lucía Megías [2007/2009:48]: «En la situación actual, la del "incunable del hipertexto", tendemos a crear grandes proyectos editoriales que en sí son una isla de información: cada uno con sus estándares, sus modelos y lenguajes. Más allá de los lenguajes generales, como XML o SGML anterior, lo cierto es que TEI [...] quiere ser el que ocupe este puesto de estándar universal. Los problemas son muchos, los interrogantes aún más, pero lo cierto es que sólo podremos llegar a construir una verdadera comunidad de ediciones si potenciamos los estándares». 
6. Las dificultades que se pueden encontrar todavía en la edición crítica digital, elijamos el software o lenguaje que elijamos, aconsejan la selección de un corpus reducido de obras para la experimentación.

7. Prolope anhelaría la creación de un software para la realización de ediciones críticas del teatro del Siglo de Oro de uso amigable y sencillo que pudieran utilizar sus colaboradores.

8. Llegados a ese punto, cabría plantearse incluso la posibilidad de que el texto crítico del proyecto principal, las comedias transmitidas en Partes, naciera en formato digital y pudiera ser procesado y publicado digitalmente en el futuro, independientemente de que su primer destino sea la publicación en papel. Paralelamente, los textos críticos de las ediciones nacidas en papel y ya publicadas, pueden ser digitalizados y publicados.

9. Todos los textos que Prolope edite digitalmente tendrán el mismo nivel de exigencia en cuanto al rigor filológico para su establecimiento que los que viene ofreciendo en papel. ${ }^{46}$

Todo llegará... Por ahora, nos interesa compartir estas reflexiones y planteamientos, estas conclusiones y estos puntos de partida y... empecemos cuanto antes a experimentar y a publicar en red.

46 Estas conclusiones y las líneas maestras de este artículo han sido aprobadas y asumidas por el Comité Científico de Prolope, conformado por Alberto Blecua, Enrico di Pastena, Victoria Pineda, Gonzalo Pontón, Marco Presotto y yo mismo. Marco Presotto remitirá un artículo sobre su edición digital de La dama boba para su publicación en el próximo número, XXI, del Anuario Lope de Vega. 


\section{BIBLIOGRAFÍA}

Andrés de Poza. Edición digital de textos múltiples, proyecto dirigido por Carmen Isasi, http://andresdepoza.com/, consultada el 20 de octubre de 2013.

Balme, Christopher B., The Cambridge Introduction to Theatre Studies, Cambridge University Press, Cambridge, 2008.

Blecua, Alberto, Manual de Crítica Textual, Castalia, Madrid, 1983.

Calderón de la Barca, Pedro, El divino cazador, ed. E. Pellús Pérez, Biblioteca Virtual Miguel de Cervantes, Alicante, 2000, http://www.cervantesvirtual. com/obra/el-divino-cazador/, consultado el 30 de septiembre de 2013.

CAPOIA, Stefania, ed., «Lope de Vega Carpio», tesis de licenciatura inédita dirigida por Marco Presotto y presentada en la Università Ca' Foscari, Venecia, 2005.

Casa di Lope, www.casadilope.it, proyecto y página dirigidos por F. Antonucci. Consultada el 27 de septiembre de 2013.

Cervantes SaAvedra, Miguel de, La entretenida, ed. John O'Neill, proyecto «Out of the wings», King's College, Londres, 2013, http://entretenida.outofthewings. org/index.html, consultada el 30 de septiembre de 2013.

Cuenca Muñoz, Paloma, «La edición paleográfica de textos teatrales clásicos: La encomienda bien guardada de Lope de Vega», $V$ Jornadas Científicas sobre Documentación de Castilla e Indias en el siglo XVII, Departamento de Ciencias y Técnicas Historiográficas, Universidad Complutense de Madrid, Madrid, 2006, pp. 93-103.

An Electronic Corpus of 15th Century Castilian Cancionero Manuscripts, proyecto dirigido por D. S. Severin en la University of Liverpool, http://cancionerovirtual.liv.ac.uk/, consultada el 19 de octubre de 2013.

García Reidy, Alejandro, Gonzalo Pontón y Ramón Valdés, «El teatro de Lope de Vega en el nuevo siglo», Ínsula, 802, 2013, pp. 9-12.

Giunta, Claudio, «Prestigio storico dei testimoni e ultima volontà dell'autore», Anticomoderno, III, 1997, pp. 169-198. Se cita por la versión alojada en la página

del autor, www.claudiogiunta.it, consultada el 5 de marzo de 2012.

Internet Shakespeare Editions, internetshakespeare.uvic.ca.

Julí́ MarTínez, Eduardo, ed., Lope de Vega, La buena guarda, en Obras dramáticas escogidas, Librería y casa editorial Hernando, Madrid, 1934-1935, volumen I. 
JUXTA, http://www.juxtasoftware.org/, consultada el 27 de septiembre de 2013.

Keene, Suzanne, «Now you see it, now you won't. Preserving digital cultural material», en D. Bearman y J. Trant, eds. Museums and the Web 2002. Archives \& Museum Informatics, Toronto, 2002. Se cita por http://www. slideshare.net/ashtreex/now-you-see-it-now-you-wont, consultada el 25 de septiembre de 2013.

Lucía Megías, José Manuel, «La edición crítica hipertextual. Hacia la superación del incunable del hipertexto», 2007, en el repositorio open acces de la Universidad Complutense de Madrid: http://eprints.ucm.es/6517/, consultada el 21 de agosto de 2013 [se cita por esta versión]; y en Cristina Castillo Martínez y José Luis Ramírez Luengo (coords.) Lecturas y textos en el siglo XXI: nuevos caminos en la edición textual, Axac, Lugo, 2009, pp. 11-74.

Lucía Megías, José Manuel, «Enredando con el teatro español de los siglos de oro en la web: de los materiales actuales a las plataformas de edición», Signa, 17, 2008, pp. 85-129. http://cervantesvirtual.com/hemeroteca/signa/, consultada el 28 de septiembre de 2013.

Mazzocchi, Giuseppe, ed., Lope de Vega, Juan de Dios y Antón Martín, en Comedias de Lope de Vega. Parte X, vol. III, UAB-Milenio, Lérida, 2010, pp. 1363-1508. Morrás, María, «Informática y crítica textual: realidades y deseos», en Literatura hipertextual y teoría literaria, ed. María José Vega, Mare Nostrum, Madrid, 2003, pp. 225-240.

MuÑoz Pons, Carlos, «El proceso de edición digital en ARTELOPE y CTCE», Teatro de palabras [en línea], 7 (2013), pp. 483-496.

Nogales Flores, J. Tomás, "XML aplicado a la literatura: introducción a TEI», http://rayuela.uc3m.es/ nogales/cursos/tei.html, creada en 2002, última actualización en 2006, consultada el 30 de agosto de 2013.

Nogales Flores, J. Tomás, B. Martín Galán, M. C. Arellano Pardo y M. C. Sebastián, «Una experiencia de aplicación de XML y TEI a obras teatrales del Siglo de Oro español», en Los sistemas de información en las organizaciones: eficacia y transparencia, [VIII Jornadas Españolas de Documentación, Barcelona, 6, 7 y 8 de febrero de 2003], Col legi Oficial de Bibliotecaris Documentalistes de Barcelona - FESABID, Barcelona, 2003, pp. 395-404. Alojado en el e-archivo de la Universidad Carlos III: http://e-archivo.uc3m.es/handle/10016/906, consultado el 31 de agosto de 2013. 
Numerico, T., D. Fiormonte y F. Tomasi, L’umanista digitale, Il Mulino, Bolonia, 2010. O'Donnell, Daniel Paul, «The Doomsday Machine, or, "If you build it, will they still come ten years from now?" What Medievalists working in digital media can do to ensure the longevity of their research», Electronic Medievalia, 7, 2004, http://www.mun.ca/mst/heroicage/issues/7/ecolumn.html, consultada el 27 de septiembre de 2013.

Profeti, Maria Grazia, «Comedias representadas-textos literarios: los problemas ecdóticos», en C. Hernández Valcárcel, ed., Teatro, historia y sociedad, Universidad de Murcia-Universidad Autónoma de Ciudad Juárez, MurciaCiudad Juárez, 1996, pp. 205-216.

Pusceddu, Cinzia, «Risorse digitali per la Filologia», apéndice a Domenico Fiormonte, Scrittura e Filologia nell'era digitale, Bollati Boringhieri, Turín, 2003.

Prolope, ed., Lope de Vega, El castigo sin venganza. Textos de dramaturgia, estudios, guía didáctica y edición crítica en colaboración de Rakatá y PROLOPE, PPU, Barcelona, 2011.

Querol Coll, Enric, ed., Lope de Vega, La bella malmaridada, en Comedias de Lope de Vega, Parte II, vol. II, UAB-Milenio, Lérida, 1998, pp. 1175-1389.

Rodríguez Rodríguez, José Javier, ed., Lope de Vega, El blasón de los Chaves de Villalba, en Comedias de Lope de Vega. Parte X, vol. III, UAB-Milenio, Lérida, 2010, pp. 1187-1361.

Serrano Deza, Ricardo, Manual de análisis infoasistido de textos aplicado al teatro de los Siglos de Oro, Universidad Nacional de Educación a Distancia, Madrid, 2001.

Severin, D. S., «An Electronic Corpus of 15th Century Castilian Cancionero Manuscripts», http://cancionerovirtual.liv.ac.uk/, consultada el 11 de septiembre de 2013.

Teatro de palabras. Revista sobre teatro áureo [en línea], 7, 2013: Lope de Vega y el teatro clásico español: nuevas estrategias de conocimiento en humanidades. Consultado el 18 de octubre de 2013.

Teatro de los Siglos de Oro. Portal editado por Ricardo Serrano Deza y Alfredo Hermenegildo en la Université du Québec à Trois-Rivières, http://www.uqtr. ca/teatro/entrada/t.html, consultada el 20 de octubre de 2013.

TESORO, proyecto de edición electrónica del teatro Español del Siglo de Oro para la difusión del español y la formación a distancia, http://www.bib.uc3m.es/ nogales/xml/tesoro/index.html\#enti, consultada el 1 de septiembre de 2013. 
The Cervantes Project, proyecto dirigido por Eduardo Urbina en la Texas A\&M University, http://cervantes.tamu.edu/, consultada el 19 de octubre de 2013. Valdés Gázquez, Ramón, ed., Lope de Vega, La batalla del honor, en Comedias de Lope de Vega, Parte VI, vol. I., UAB-Milenio, Lérida, 2005, pp. 67-292.

VALdÉs GÁzquez, Ramón, «Los Sueños de Quevedo: variantes, versiones y estrategias de edición", en La escondida senda. Estudios en homenaje a Alberto Blecua, Barcelona, Castalia, 2012, pp. 385-423.

VEGA GARCíA-LuEngos, Germán, «Herramientas informáticas para la investigación y la docencia del teatro áureo español», actualizado en colaboración con Fausta Antonucci, en La casa di Lope, http://www.casadilope.it/enlaces-comentados/ enlaces-comentados.html, consultada el 30 de septiembre de 2013. 